\title{
Parents' verbal communication and childhood anxiety: a systematic review
}

Article

Accepted Version

Percy, R., Creswell, C., Garner, M., O'Brien, D. and Murray, L. (2016) Parents' verbal communication and childhood anxiety: a systematic review. Clinical Child and Family Psychology Review, 19 (1). pp. 55-75. ISSN 1573-2827 doi: https://doi.org/10.1007/s10567-015-0198-2 Available at https://centaur.reading.ac.uk/46745/

It is advisable to refer to the publisher's version if you intend to cite from the work. See Guidance on citing.

To link to this article DOI: http://dx.doi.org/10.1007/s10567-015-0198-2

Publisher: Springer

All outputs in CentAUR are protected by Intellectual Property Rights law, including copyright law. Copyright and IPR is retained by the creators or other copyright holders. Terms and conditions for use of this material are defined in the End User Agreement.

\section{www.reading.ac.uk/centaur}

\section{CentAUR}

Central Archive at the University of Reading 
Reading's research outputs online 
Parents' verbal communication and childhood anxiety: A systematic review

Ray Percy ${ }^{1}$, Cathy Creswell ${ }^{1}$, Matt Garner ${ }^{2}$, Doireann O’Brien ${ }^{1}$, \& Lynne Murray ${ }^{1,3}$

${ }^{1}$ Department of Psychology, University of Reading, United Kingdom

${ }^{2}$ Department of Psychology, University of Southampton, United Kingdom

${ }^{3}$ Department of Psychology, Stellenbosch University, South Africa

Address for correspondence and reprint requests to: Dr Ray Percy, School of Psychology and Clinical Language Sciences, University of Reading, RG6 6AL; Phone: 0118378 5260; Fax 0118378 6665; e-mail: r.s.percy@reading.ac.uk 


\begin{abstract}
Parents' verbal communication to their child, particularly the expression of fear-relevant information (e.g., attributions of threat to the environment), is considered to play a key role in children's fears and anxiety. This review considers the extent to which parental verbal communication is associated with child anxiety by examining research that has employed objective observational methods. Using a systematic search strategy, we identified 15 studies that addressed this question. These studies provided some evidence that particular fearrelevant features of parental verbal communication are associated with child anxiety under certain conditions. However, the scope for drawing reliable, general conclusions was limited by extensive methodological variation between studies, particularly in terms of the features of parental verbal communication examined and the context in which communication took place, how child anxiety was measured, and inconsistent consideration of factors that may moderate the verbal communication-child anxiety relationship. We discuss ways in which future research can contribute to this developing evidence base and reduce further methodological inconsistency so as to inform interventions for children with anxiety problems.
\end{abstract}

Keywords: child anxiety, parenting, verbal communication 
Anxiety disorders are common in childhood (Ford, Goodman, \& Meltzer, 2003), affecting up to $9 \%$ of pre-schoolers and approximately $12 \%$ of primary school-aged children (Egger \& Angold, 2006; Lavigne et al., 1996; Wichstrom et al., 2012; Costello, Egger, Copeland, Erkanli, \& Angold, 2011). Without treatment, these disorders persist (Bittner et al., 2007; Woodward \& Fergusson, 2001), and are associated with further difficulties including depression, behavior disorders, and impaired social and educational functioning (Bittner et al., 2007; Hughes, Lourea-Waddell, \& Kendall, 2008; Woodward \& Fergusson, 2001). When anxiety disorders persist into adulthood, they are associated with a range of adverse outcomes including impaired occupational functioning (Kessler \& Frank, 1997), elevated risk of suicidal ideation and suicide attempts (Kessler, Borges, \& Walters, 1999), and overall reduced quality of life (Comer et al., 2011). Furthermore, anxiety disorders that originate in youth, compared to those that originate in adulthood, are associated with greater severity, increased comorbidity, and greater likelihood of relapse following periods of remission (Ramsawh, Weisberg, Dyck, Stout, \& Martin, 2012). Together, these findings highlight the need for a good understanding of how child anxiety disorders develop to guide the advancement of preventive and therapeutic interventions.

One area of research that has provided insight into the aetiology of child anxiety disorders is the study of familial aggregation. Specifically, intergenerational studies have demonstrated that both children of parents with anxiety disorders (Biedel \& Turner, 1997; Spence, Najman, Bor, O’Callaghan, \& Williams, 2002), and parents of children with anxiety disorders (Cooper, Fearn, Willetts, Seabrook, \& Parkinson, 2006; Francis, \& Grubb, 1987; Lieb et al., 2000), are approximately five times more at-risk of anxiety disorder relative to the base rate. Notably, genetic factors are likely to account for only about one third of the riskrelated variance for anxiety disorder, with the remainder accounted for by environmental factors (Gregory \& Eley, 2007; Hettema, Neale, \& Kendler, 2001).

Given the modest contribution of genetic factors to the familial aggregation of anxiety disorders, theoretical accounts of the development and maintenance of child anxiety have suggested that certain parenting practices play a key role (Hudson \& Rapee, 2004; Murray, Creswell, \& Cooper, 2009; Rubin, Coplan, \& Bowker, 2009). Specifically, it has been proposed that the risk of child anxiety is raised by exposure to parenting behaviors that limit the child's opportunities to gain mastery over their environment, including over-controlling and overprotective behavior (i.e., reduced encouragement/autonomy promotion) and 
parenting behaviors that model anxious responses (e.g., Murray et al., 2009). These behaviors are thought to impede the development of strategies necessary for the child to manage difficulties independently, leading to anxiety when they are faced with novelty or challenge.

A second, potentially overlapping, parenting dimension highlighted in learning theories of anxiety development (i.e., Bandura, 1986; Rachman, 1977, 1991) is the transfer of verbal fear-relevant information from parent to child (Fisak \& Grills-Taquechel, 2007; Murray et al., 2009). This focus is consistent with a large volume of research on parent-child interactions in non-clinical populations, where the emotional content of parental discourse has been found to be an important predictor of children's socio-emotional cognitions and functioning (e.g., Denham, Zoller, \& Couchard, 1994; Dunn, Bretherton, \& Munn, 1987; Dunn, Brown, \& Beardsall, 1991; Ruffman, Slade, Devitt, \& Crowe, 2006; Taumoepeau \& Ruffman, 2008), including the child's understanding of links between their own and others' internal states and behaviors (Fivush, Haden, \& Reese, 2006; Fivush \& Nelson, 2006), as well as child internalising symptoms (Sales \& Fivush, 2005). Notably, there is some evidence that child socioemotional outcome is more strongly associated with how parents speak to their children than with general parental behavior, suggesting that parent-child conversations may be an especially important context in which children learn to make sense of their experience (Raikes \& Thompson, 2006; Ruffman et al., 2006). With regard to the transmission of anxiety, fear-relevant verbal information includes messages that indicate threat explicitly (e.g., “...those children are mean”), and messages that suggest threat implicitly by, for example, emphasising the child's vulnerability (e.g., “...you'll be frightened”) or promoting/endorsing avoidance of feared situations (e.g., “...don't climb too high”). Messages that serve an over-controlling function and, as a result, limit the child's opportunities to gain mastery over their environment are also likely to be implicated (e.g., “...do it this way”) (Fisak \& Grills-Taquechel, 2007).

The importance of the verbal fear-relevant information pathway in the development of child fears has received support from an influential series of experimental studies with nonclinical children. These studies have demonstrated that receipt of negative verbal information under controlled conditions increases children's anxious beliefs and behaviors, whereas positive information typically has the opposite effect (Field, Hamilton, Knowles, \& Plews, 2003; Field \& Lawson, 2003; Field, Lawson, \& Banerjee, 2008; Lawson, Banerjee, \& Field, 2007; Muris, van Zwol, Huijding, \& Mayer, 2010; Remmerswaal, Muris, Mayer, and Smeets, 
2010). For example, Field and Lawson (2003) provided children with either positive, threat, or no information about novel animals; as predicted, both positive and threat information had significant effects on child fear beliefs and avoidant behaviors concerning a box presumed to contain the animal, such that fear beliefs and avoidance decreased following positive information and increased following threat information. Importantly, these experimentally induced beliefs have been shown to last for up to 6 months (Field et al., 2008), indicating that the acquisition of threat information may have enduring consequences for child fears. Similar effects have been demonstrated in relation to child fears about novel social situations (i.e., public speaking) (Field et al., 2003). Although experimental studies that have examined the effects of verbal threat (or otherwise negative) information on children's fears have yielded interesting and important findings, the usefulness of these findings is limited by the degree to which they extend to children's everyday experiences of verbal information relevant to fear acquisition. Above all, in the research to date, the source of verbal information has typically been an unfamiliar adult, a teacher, or a peer. This is significant, because outside of experimental settings many anxiety-related learning experiences are likely to be provided by children's parents (Fisak \& Grills-Taquechel, 2007). Furthermore, as discussed earlier, evidence from the normal developmental literature suggests that parental verbal communication may be a particularly important factor in relation to children's socioemotional understanding and functioning (e.g., Dunn et al., 1987, 1991; Fivush \& Nelson, 2006; Ruffman et al., 2006; Sales \& Fivush, 2005).

Where previous reviews have considered the role of parental verbal communication of fear-relevant information in child anxiety, they have typically included studies that examined non-verbal parenting behavior (e.g., Fisak \& Grills-Taquechel), or studies in which parents were not the source of fear-relevant information (e.g., Muris \& Field, 2010). Furthermore, previous reviews have typically included studies that used a broad range of methods, including both observations of actual parent verbal communication and measures of child or parent perceived verbal communication, on the basis of (sometimes retrospective) child or parent report questionnaires (e.g., Fisak \& Grills-Taquechel, 2007; Rapee, 2012), making it difficult to draw conclusions on what is actually being measured. The potential limitation of combining these different approaches is highlighted by the fact that, in the case of parental behaviors more broadly, studies that have relied on parent or child self-report data have been much less consistent in establishing associations with child anxiety than those that have used 
observational measures (Wood, McLeod, Sigman, Hwang, \& Chu, 2003). Moreover, there is strong evidence that parent and child reports of parenting often differ significantly, suggesting that one or both informants' reports may be biased in some way (for a review of this literature see Taber, 2010). Given the limitations of non-observational approaches, the emphasis of the current review is on studies that have used observational methods to examine parental verbal communication and its association with child anxiety symptoms and disorder. The aim of the review was to identify and evaluate the empirical literature in this area to address the following question: To what extent is parents' directly observed verbalcommunication to their child associated with childhood fears and anxiety?

\section{Method}

\section{Definitions and Inclusion/Exclusion Criteria}

The review was restricted to articles that described studies that generated quantitative data concerning the association between observations of parental verbal communication and child anxiety. Verbal communication was defined as overt verbal expression in the presence of offspring, measured independently from behavioral communication (e.g., facial expression, body language etc.). Consistent with previous reviews (e.g., McLeod, Wood, \& Weisz, 2007), the term anxiety encompassed anxiety disorders (i.e., clusters of anxiety symptoms that cause distress and impaired functioning) and symptoms of anxiety/fear/worry not unique to a single disorder (e.g., self-reported fear beliefs, observed anxious/avoidant behavior), but not risk factors for anxiety (e.g., anxiety-related cognitive biases). Studies must have measured child anxiety independently (either cross-sectionally or longitudinally) from other aspects of child functioning (e.g., depressive symptoms). A study was included if the mean age of child participants was 18 years or younger. To ensure that the evidence regarding the association between observations of parental verbal communication and child anxiety was as free from potential confounds as possible, studies that recruited participants from any of the following populations were excluded: (a) children/parents with a primary psychiatric diagnosis other than an anxiety disorder; (b) children from a non-typical population other than those with anxiety disorders (e.g., children with an intellectual/neurological impairment, autistic spectrum condition, physical disability, or lifelimiting illness); and (c) parents from a non-typical population other than those with anxiety disorders (e.g., maltreating parents). Studies that specifically investigated the effects of 
psychotropic medication or used a single-case design were also excluded. To ensure only high quality research was included in the review, studies must have been published in peer reviewed journals (no dissertations). For practical reasons, articles must have been published in English (no papers were excluded on this basis).

\section{Identification of Relevant Literature}

A search of internet-based bibliographic databases (PsycINFO and Web of Science) was conducted, covering January 1980 to the end of March 2015. In the PsycINFO search, articles indexed under the following subject terms (or related terms) as major concepts were retrieved: (a) parent-child communication, and (b) anxiety or cognitive development. Articles retrieved via PsycINFO were also required to contain each of the following terms (or related terms) in their abstract: (a) parent, (b) child, and (c) conversation. A follow-up PsycINFO search was conducted to retrieve articles containing the following terms (or related terms) in their title: (a) parent, (b) child, (c) communication, and (d) anxiety or cognitive development ${ }^{1}$. In the Web of Science search, articles were initially retrieved using the same approach used for the follow-up PsycINFO search. A follow-up Web of Science search was conducted, using the same combination of search terms, to retrieve articles indexed by topic. Each Web of Science search was conducted using the SCI-EXPANDED and SSCI subdatabases; results were limited to the following categories: (a) psychology; (b) psychology, clinical; (c) psychology, developmental; (d) psychology, experimental; (e) psychology, multidisciplinary; and (f) family studies. Full search criteria are available on request.

Following the search of electronic databases, abstracts were screened and full-text articles for relevant studies were reviewed for eligibility by a postdoctoral/Clinical Psychologist (R. P.). Next, reference lists of retained articles were inspected for relevant studies; bibliographic databases were used again to retrieve abstracts and, if appropriate, fulltext articles. Finally, other articles known to be eligible for the review were added to the body of retained literature. A second member of the team, who was studying for a $\mathrm{PhD}$. in psychology (D. OB.), independently rated studies for inclusion/exclusion. Discrepancies

\footnotetext{
${ }^{1}$ Search terms related to cognitive development were included on the basis that there is a well-established body of literature regarding associations between parental verbal communication and normal child development, and it was considered studies in this area may have used measures relevant to child anxiety.
} 
between the first and second rater were resolved by another independent member of the team (C. C.).

\section{Literature Search Results}

The search procedure is illustrated in Figure 1. The initial PsycINFO and Web of Science searches retrieved 120 and 150 citations respectively; the follow-up PsycINFO search retrieved 157 citations; the follow-up Web of Science search was abandoned due to retrieving an excessive number of citations $(\approx 7,000)$. Thus, database searching resulted in the identification of 427 citations, of which 146 were duplicates. Two further articles, already known to be eligible for the review, were added to the list of citations. Accordingly, 283 abstracts were screened for eligibility. Abstract screening led to the exclusion of 187 articles (see Figure 1 for exclusion reasons); full-text articles for the remaining 96 citations were reviewed for eligibility. Of these, 81 articles were excluded and 15 described studies eligible for the review. Inspection of the reference lists of retained articles did not result in the identification of any additional eligible studies. Reliability between the first and second rater concerning the inclusion/exclusion of studies was $96.5 \%$, kappa $=.72$. Ten disagreements between the first and second rater were resolved by the third independent rater.

Figure 1 about here

\section{Information Extracted}

The following information was extracted from each study: (a) Design features, including study location and setting; (b) sample characteristics, including child sex, child age, child anxiety diagnostic status, parent sex, parent age, parent anxiety diagnostic status, and family ethnicity; (c) verbal communication assessment paradigm; (d) verbal communication features measured; (e) verbal communication assessment strategy (i.e., continuous or categorical); (f) verbal communication coding unit (e.g., utterance, word, sentence); (g) verbal communication measure reliability; (h) child anxiety measure; (i) measurement technology of child anxiety measure (i.e., questionnaire, interview, behavioral observation); (j) child anxiety assessment strategy (i.e., continuous or categorical); and (k) child anxiety 
informant. Information regarding the association between observed parental verbal communication and child anxiety was also extracted from each study. Where possible (i.e., where sufficient data was available), this included extracting effect sizes for statistically significant results in terms of Pearson's product-moment correlation coefficient $(r)$. Where studies did not provide effect sizes or reported effect sizes not in term of $r$, effect sizes were calculated or converted to $r$ using an online calculator (http://www.psychometrica.de/effect_size.html). Effect sizes were interpreted according to Cohen's (1988) definition of an effect size, as follows: at least .10 as 'small effect', at least .24 as 'medium effect', and at least .37 as 'large effect'. Where effect sizes are not reported below this is because the necessary data was not provided.

\section{Study and Participant Characteristics}

Table 1 provides a comprehensive overview of the core characteristics of the reviewed studies. The following sections summarise these characteristics in order to highlight the critical similarities and differences between studies included in the review.

The 15 identified studies were published from 1996 to 2015. Ten studies (66.7\%) were conducted in the United States, with the remainder carried out in the Netherlands (three studies; $20.5 \%$ ), Australia (one study; 6.7\%), or the United Kingdom (one study; 6.7\%). Eleven studies (73.3\%) were cross-sectional, one study (6.7\%) was longitudinal, and three studies $(20.0 \%)$ employed experimental designs. Five studies (33.3\%) recruited parent-child dyads from child mental health clinics, two (13.3\%) from adult mental health clinics, and one (6.7\%) from both adult and child mental health clinics. Of the remaining seven studies, six $(40.0 \%)$ recruited dyads through schools only, and one $(6.7 \%)$ recruited dyads from a community sample of mothers attending antenatal clinics. All 15 studies included children of both sexes. The age of study children ranged from 3 to 15 years, with a mean intra-study age range of 4.9 years. Seven studies $(46.7 \%)$ included parents of both sexes. In the remaining eight $(53.3 \%)$, the focus was solely on mothers. Thirteen studies $(86.7 \%)$ reported on ethnicity, and of these, between $67 \%$ and $100 \%$ of children were Caucasian. 
Table 1 about here

\section{Parents' Verbal Communication}

Table 2 provides a comprehensive overview of the approach taken to measure parents' verbal communication in each study.

Context. Five studies (33.3\%) measured parental verbal communication during parentchild discussions prompted by ambiguous vignettes. For example, Remmerswaal et al. (2010) used vignettes describing encounters with an unfamiliar animal, while Murray et al. (2014) used a storybook that described situations that a child might encounter on their first day at school.

Five studies (33.3\%) measured parents' verbal communication to their child during discussions about the child's past experience and for three of these, data were collected and combined across multiple discussion tasks. For example, in Moore, Whaley, and Sigman (2004) parents' verbal communication was measured across a discussion of one event when the child had experienced anxiety and one that involved parent-child conflict. Of the other two studies, one collected parental verbal communication data from a single discussion about parent-child conflict, while the other collected data from three discussions (i.e., about the child's experience of anxiety, anger, and happiness) and analysed data for each separately.

Five studies (33.3\%) measured parental verbal communication whilst the child engaged in a challenging activity. For example, Turner, Beidel, Roberson-Nay, and Tervo (2003) observed parents' verbal communication whilst their child engaged in 'risky' play, while Hummel and Gross (2001) did so whilst children attempted to solve a puzzle. Remmerswaal, Muris, and Huidjing (2013) measured parental verbal communication whilst the parent prepared the child for an encounter with an unfamiliar animal.

Features of verbal communication. The 15 reviewed studies measured a total of 41 different features of parental verbal communication. Only five of these variables (12.2\%) were measured in more than one study. Specifically, 'catastrophizing' was measured in two 
studies, 'negative emotion words' was measured in two studies, 'negative statements' was measured in three studies, 'explanatory language' was measured in two studies, and 'discouragement of emotion talk' was measured in two studies. The verbal communication features measured can be grouped into five categories, as follows: (a) threat-related verbal communication, (b) other negative verbal communication, (c) verbal communication hypothesised to reflect parental over-control, (d) positive verbal communication, and (e) general features of verbal communication (see Tables 3 and 4).

Measurement strategy. Fourteen studies (93.3\%) included continuous measures of parental verbal communication, such as frequency counts of specific verbal communication features, or overall ratings of certain features on Likert-type scales. Three studies $(20.0 \%)$ included categorical measures of parental verbal communication, such as rating certain features as being 'present' versus 'absent' or rating them as being 'high level' versus 'low level'.

The units of measurement of parental verbal communication included individual words (3 studies; 20\%), 'statements' (4 studies; 26.7\%), 'utterances' (3 studies; 20\%), 'sentences' (1 study; 6.7\%), and whole conversations (3 studies; 20\%). One study (6.7\%) did not report the unit of measurement for any verbal communication variables, and two studies (13.3\%) did not report the unit of measurement for at least one verbal communication variable.

Measurement reliability. Twelve studies $(80.0 \%)$ reported interrater reliability for coded parental verbal communication. Where reliability was reported, values of Kappa were $\geq .61$ and values of $r$ were $\geq .66$.

Table 2 about here

\section{Measurement of Child Anxiety}

Six studies (40\%) assessed children's anxiety using self- or parent-report questionnaires. Specifically, these were the Fear Beliefs Questionnaire (FBQ) (Muris et al., 2010; Remmerswaal et al., 2010, 2013), the child report Screen for Child Anxiety Related 
Emotional Disorders (SCARED) (Brumariu \& Kerns, 2015), the Social Phobia Anxiety Inventory for Children (SPAI-C) (Hummel and Gross (2001), or the parent-report Child Behavior Checklist anxiety subscale(CBCL) (Hane \& Barrios, 2011). One of these studies also measured children's observed avoidance behavior using a behavioral approach task (Remmerswaal et al., 2013).

The remaining nine studies (60\%) used diagnostic assessments of anxiety disorders in children. Eight of these carried out separate diagnostic interviews with children and parents and considered both informants' reports to determine child anxiety diagnostic status using either the Anxiety Disorders Interview Schedule for DSM-IV (ADIS-IV-C/P) (Dadds, Barrett, Rapee, \& Ryan.1996; Hosey and Woodruff-Borden, 2012; Schrock and WoodruffBorden, 2010; Suveg et al., 2008; Suveg, Zeman, Flannery-Schroeder, \& Cassano, 2005), or the Schedule for Affective Disorders and Schizophrenia for School-age Children (K-SADS) (Turner et al., 2003; Whaley, Pinto, \& Sigman, 1999), or both (Moore et al., 2004). Murray et al. (2014) relied solely on the parent version of the ADIS-IV. Eight of these studies assessed children for the presence of any anxiety disorder (Dadds et al., 1996; Hosey and WoodruffBorden, 2012; Moore et al.,2004; Schrock and Woodruff-Borden, 2010; Suveg et al., 2005, 2008; Turner et al., 2003; Whaley et al., 1999), and one assessed for the presence of social phobia only (Murray et al., 2014). Half of these studies included parents who themselves were identified as having an anxiety disorder (see next paragraph).

\section{Results}

\section{Evidence for an Association between Observed Parental Verbal Communication and Child Anxiety}

The association between parenting and childhood anxiety has been shown to be significantly stronger for samples comprised solely of children diagnosed with anxiety disorders as compared to samples of children drawn from community populations (who may or may not have anxiety disorders) (McLeod et al., 2007). This suggests that the parentingchildhood anxiety relationship may be moderated by child anxiety diagnostic status. Accordingly, we classified studies into groups based on whether they categorised child participants on the basis of anxiety disorder status. Specifically, studies were divided into (i) those in which child participants were drawn from community/school populations where child anxiety was assessed by continuous scores on questionnaire measures (and therefore 
samples may or may not have included children with anxiety disorders), and (ii) those that explicitly compared children with and without anxiety disorders. An overview of the principal findings is presented in Table 3 and Table 4.

Evidence from studies of community populations. Consistent with previous reviews (i.e., Muris \& Field, 2010), which have distinguished between the cognitive and behavioral components of fear based on established theoretical models (see Lang, 1968, 1985; Merckelbach et al., 1996), we have distinguished between studies that examined fear beliefs and anxious behaviors specifically, and those that examined anxiety symptoms more generally.

\section{Associations between parental verbal communication and child fear beliefs and}

behaviors. All three of the studies that examined associations between parental verbal communication and children's fear beliefs and (in one case) avoidance behavior took an experimental approach in which parents were instructed to provide their child with negative (i.e., threat), positive, or (in one case) ambiguous information during vignette-prompted open-ended parent-child discussions about unfamiliar animals (Muris et al., 2010; Remmerswaal et al., 2013), or when the child was preparing to put their hand into the animal container (Remmerswaal et al., 2013). The experimental manipulation was successful in all three of these studies in terms of the amount of negative information parents in the different conditions gave their child. Specifically, parents instructed to provide their child with negative information made significantly more negative statements than parents provided with either positive information (Muris et al., 2010; Remmerswaal et al., 2010, 2013) or ambiguous information (Muris et al., 2010). Just one study tested the manipulation in relation to the amount of positive information parents gave their child, and results indicated that parents instructed to provide their child with positive information made significantly more positive statements than parents instructed to provide their child with negative information (Remmerswaal et al., 2013). Results of two of the studies indicated that children's selfreported fears concerning the animals increased from pre- to post-discussion when their parents provided negative (i.e., threatening) verbal information (Muris et al., 2010; Remmerswaal et al., 2010). While data were not available to calculate the size of these effects, it was possible to determine that in Remmerswaal et al (2010) the significant postdiscussion difference in fear beliefs between children in the different information conditions in (i.e., children who received negative information reported significantly higher levels of 
fear than children who received positive information) represented a large effect $(r=.81)$. Muris et al. (2010) and Remmerswaal et al's (2010) findings were not replicated by Remmerswaal et al. (2013), where fear beliefs of children in the negative and positive information conditions did not differ, even though children in the negative information condition took significantly longer to put their hand into a box containing the animal than children in the positive information condition.

Associations between parental verbal communication and child anxiety symptoms. There was some evidence that children of parents who tended to develop (i.e., elaborate) threat-related themes during parent-child discussions had more parent-reported anxiety symptoms than children of parents who tended not to develop threat-related themes, with an effect in the large range $(r=.48$ ) (Hane \& Barrios, 2011). Notably, however, higher levels of general parental elaboration (e.g., bringing up new information about any topic) were associated with lower levels of child self-reported anxiety symptoms, with a small-medium effect $(r=.22)$ (Brumariu \& Kerns, 2015). In the one study that looked at the association between parents' positive verbal communication and children's anxiety symptoms, no significant effect was found (Hane \& Barrios, 2011).

Table 3 about here

Evidence from studies of children with anxiety disorders. Five of the studies that examined associations between parental verbal communication and child anxiety disorder status looked at one or more threat-related parental verbal communication variables (Dadds et al., 1996; Moore et al, 2004; Murray et al., 2014; Turner et al., 2003; Whaley et al., 1999), and in most cases (i.e., 57.1\%) these variables were not significantly associated with child anxiety disorder status (see Table 4). However, the following threat-related variables were significantly positively associated with the presence of child anxiety disorder: 'overall threat' (Dadds et al., 1996), 'catastrophizing' (Moore et al., 2004; Whaley et al., 1999), and 'threat attribution' (Murray et al., 2014). Effect sizes were calculable for all of these variables other than 'catastrophizing' in Moore et al. (2004), and all effects were in the large range ( $r=.40$ for 'threat attribution' [Murray et al., 2014] to .46 for 'catastrophizing' [Whaley et al., 
1999]).

From the six studies that examined 'otherwise negative' parental verbal communication, three of five variables were significantly associated with the presence of child anxiety disorder (see Table 4): 'negative feedback' (Hummel \& Gross, 2001), 'negative interaction' $(r=.14)^{2}$ (Schrock \& Woodruff-Borden, 2010), and 'negative emotion words' ( $r$ $=.30$ ) (Hosey \& Woodruff-Borden, 2012) (although in the case of 'negative emotion words' this association was not significant in the study of Suveg et al., 2005). Of the remaining two 'otherwise negative' verbal communication variables, parents' use of 'critical statements' was not significantly associated with child anxiety disorder status (Turner et al., 2003), and parents' reference to 'aggressive solutions' was significantly negatively associated with child anxiety disorder status ( $r=.32$ to .47$)^{3}$ (Dadds et al., 1996).

In the four studies that examined parental verbal communication hypothesised to reflect over-control, results were mixed, with the presence of child anxiety disorder being significantly positively associated with parents' use of second-person pronouns $(r=.23)$ and 'exclusion' words (e.g., 'but' or 'without') ( $r=.20)$ (Hosey \& Woodruff-Borden, 2012), but significantly negatively associated with parents' use of 'negations' (e.g., 'no' or 'never') ( $r=$ .19) (Hosey \& Woodruff-Borden, 2012) and unsolicited suggestions ( $r=.24)$ (Hummel \& Gross, 2001). Child anxiety disorder status was not significantly associated with parents' use of 'commands' (Hummel \& Gross, 2001), 'over-controlling' statements (Schrock \& Woodruff-Borden, 2010), or 'directing' statements (Turner et al., 2003).

In the six studies that examined one or more positive verbal communication variables, more than half (i.e., 57.1\%) were significantly associated with child anxiety disorder status (see Table 4). Of these, three associations were in the expected direction: 'positive consequence' $(r=.41)^{4}$ (Dadds et al., 1996), 'positive feedback' $(r=.33)$ (Hummel \& Gross,

\footnotetext{
${ }^{2}$ Effect size corresponds with the effect labelled with superscript letter 'i' in Table 4. Insufficient data was reported to calculate the size of the effect labelled with superscript letter ' $j$ ' in Table 4.

${ }^{3}$ The lower effect size corresponds to the outcome of an analysis that compared parents of anxious and nonclinical control children; the higher effect size corresponds to the outcome of an analysis that compared parents of anxious and aggressive children.

${ }^{4}$ Effects size corresponds to the outcome of an analysis that compared parents of anxious and non-clinical control children; the outcome of an analysis that compared parents of anxious and aggressive children was not significant.
} 
2001), and 'positive emotion words' ( $r=.41$ ) (Suveg et al., 2005). One association was in the opposite direction to that expected: 'productive engagement' (Schrock \& Woodruff-Borden, 2010).

Finally, five studies examined one or more general parental verbal communication variables (e.g., agreements, questions, first-person pronouns - see Table 4 for other examples), and results indicated that several of these variables were significantly associated with child anxiety disorder status (see Table 4 for direction of effects for specific variables). All effect sizes were in the medium-large range, with $r=.26$ for 'explanations' (Hummel \& Gross, 2001) at the low end and $r=.48$ for 'discouragement of emotion talk' (Suveg et al., 2008) at the high end.

Table 4 about here

\section{Discussion}

\section{Summary of Main Findings}

Following on from a large body of evidence on the role of parent-child discussions in children's cognitive and socio-emotional development in non-clinical populations, research interest has grown in the topic of parental verbal behaviour and its association with child anxiety and, in the last 20 years, a number of studies have been conducted. These studies have, however, differed in several critical ways, making it difficult to draw clear conclusions. Nevertheless, given the promise of this line of investigation, it is worthwhile at this juncture to review the evidence to date and provide pointers for further investigation.

In brief, experimental studies with non-clinical children have shown that children's fear beliefs can be increased by their parents verbally communicating negative information under certain conditions (i.e., during vignette-prompted parent-child discussions about unfamiliar animals). Nevertheless, as yet, there has been no evidence that this effect generalises beyond specific controlled conditions. Additionally, the way that data has been reported in these studies means that the strength of these effects is somewhat unclear (although the one 
calculable effect size in Remmerswaal et al. [2010] indicated the possibility of a large effect). Still, these findings are consistent with the results of a larger body of experimental research with non-clinical children instigated by Field and colleagues, in which similar designs have been employed to test the effects of non-parental negative verbal communication on children's fears (e.g., Field, 2006; Field \& Lawson, 2003; Field et al., 2003). One study with non-clinical children and their parents also yielded some evidence that negative parental verbal communication can influence children's observed anxious behavior (Remmerswaal et al., 2013), which is again consistent with the results of similar research where the source of verbal communication has not been parents (e.g., Field \& Lawson, 2003). However, the small amount of data currently available (i.e., just one study) precludes firm conclusions about the association between negative parental verbal communication and non-clinical children's anxious behavior. Presently, the same must be said for the evidence concerning associations between parents': (a) negative verbal communication and non-clinical children's self- or parent-reported anxiety symptoms; (b) positive verbal communication and non-clinical children's self-reported fears, parent-reported anxiety symptoms, and observed anxious behavior; and (c) general verbal communication style (e.g., degree of elaboration) and nonclinical children's self-reported anxiety symptoms.

In contrast to the results of studies with non-clinical children, data from studies with children with anxiety disorders have generally failed to show a significant association between parents' verbal communication of threat-related information to their child and the presence of anxiety disorder in children, although some significant associations have been reported and in these cases effect sizes have been in the large range. Evidence concerning the extent to which other features of parental verbal communication are associated with anxiety disorder in children has been similarly mixed, with equally variable effect sizes, including for verbal communication features that: (a) communicate otherwise negative verbal information (i.e., not threat), (b) are hypothesised to serve a controlling function, (c) communicate positive information, and (d) reflect parents' general verbal communication style. Notably, where significant effects were reported for threat-related or other types of parents' verbal communication to their child, these were typically in the directions expected. 


\section{Limitations and Future Directions}

Although the research published to date has started to shed light on the extent to which parental verbal communication is associated with childhood anxiety, the overall picture is greatly obscured by the degree of variation in methods between studies. Specifically, eight characteristics of the empirical literature have significantly limited the scope for drawing meaningful general conclusions relevant to the question that this review aimed to address, as follows: thus, studies (a) rarely looked at comparable features of parental verbal communication or employed comparable assessment contexts; (b) varied in their theoretical grounding; (c) inconsistently looked at the effects of potential moderating variables; (d) did not directly examine how parental verbal communication may influence childhood anxiety; (e) generally used non-representative samples; (f) relied predominantly upon self- and/or parent reports of child anxiety; (g) relied on aggregated or homogenous groupings of clinically anxious children; and (h) were nearly all cross-sectional. The remainder of this discussion explores each of these limitations in turn, using specific examples to illustrate the most pertinent points and generate suggestions for the possible direction of future research.

Disparate verbal communication measures and assessment contexts. A key limitation of the body of reviewed studies is the extensive variation in the features of verbal communication that have been measured and the context in which this has taken place. That is, although some studies looked at broadly similar categories of parental verbal communication (e.g., threat-related or positive features), there was wide variation in the specific features of verbal communication measured, the units of discourse studied (e.g., sentences $v s$. individual words), and the coding strategy employed (e.g., frequency $v s$. presence/absence $v s$. overall degree of target verbalisations). Similarly, while some studies measured parental verbal communication in broadly similar contexts (e.g., parent-child discussions about ambiguous vignettes or about the child's past experience), few studies employed assessment contexts that could be considered equivalent to one another. For example, of the two studies that looked at associations between parental verbal communication and child anxiety symptoms, one study coded parental verbal communication during parent-child conversations about vignettes describing potentially threatening scenarios (Hane \& Barrios, 2011), whereas the other did so during parent-child discussions about family conflict (Brumariu \& Kerns, 2015). It is not surprising, then, that studies that have looked at the same features of parental verbal communication in equivalent contexts are very 
rare indeed (see Muris et al., 2010 and Remmerswaal et al., 2010 for exceptions). This has resulted in a collection of fundamentally isolated findings that have not yet been supported through replication, which considerably limits the scope for drawing conclusions that could inform theoretical models of childhood anxiety or clinical practice.

It is not possible in a review of this type, neither would it be useful, to thoroughly discuss all of the disparities in the features of parental verbal communication that have been assessed or the different contexts in which this has taken place. However, threat-related verbal communication, which was examined in more studies than any other discrete verbal communication subtype, can be used as an example to illustrate the main difficulties that have arisen. There was some evidence that the mere suggestion of threat by parents is less likely to be associated with child anxiety than when parents elaborate on the level of harm that their child might experience as a result of the threat. Specifically, in the study of Hane \& Barrios (2001) a significant positive association was observed between parents' tendency to develop themes of threat (i.e., threat expansion) and non-clinical children's anxiety symptoms, but the extent to which parents simply initiated themes of threat was not associated with children's anxiety symptoms. Consistent with these findings, parents' socalled negative statements (characterised by detailed threat-related language) were reliably associated with increases in children's fears in experimental studies with non-clinical children (Muris et al., 2010; Remmerswaal et al., 2010). Furthermore, evidence emerged to suggest that the extent to which parents respond to their child's anxious utterances with threat-related language (i.e., develop themes of threat) is more closely associated with the presence of anxiety disorder in children than parents' absolute use of threat-related language (Dadds et al., 1996). This latter finding also suggests that it is important to consider the reciprocal interactions between parents and children when examining the association between parental verbal communication and child anxiety, as would be predicted by theoretical models of the development and maintenance of child anxiety disorders (e.g., Murray et al., 2009). The degree to which the other threat-related verbal communication features measured in the reviewed studies captured language that developed - as opposed to initiated - themes of threat is unclear. Furthermore, it is unclear whether threat-related development/elaboration is of particular relevance to increases in child anxiety versus a more general elaborative style, although this may be suggested by findings that parents' tendency to develop topics in general during discussions with their child is significantly negatively associated with 
children's anxiety symptoms (Brumariu \& Kerns, 2015) and disorder (Suveg et al., 2008). The picture is further complicated by the fact that studies that looked at parents' threat-related verbal communication coded a variety of discourse units and employed a range of coding strategies. Thus, although variation in the specific threat-related verbal communication features that have been looked at across studies has offered an opportunity to look for potentially important patterns in the data, the extent of the variation, and the fact that it has not happened in a systematic way, precludes firm conclusions.

Differences in study methodologies may also account for inconsistent findings among the small group of experimental studies that have been conducted (Muris et al., 2010; Remmerswaal et al., 2010, 2013). Specifically, while the results of two studies indicated that children's self-reported fears concerning novel animals increased when their parents provided negative (i.e., threatening) but not positive verbal information (Muris et al., 2010; Remmerswaal et al., 2010), in Remmerswaal et al. (2013) children's fear beliefs did not differ according to whether they received negative or positive information from their parents (although children who received negative information took longer to put their hand into a box they believed to contain the animal). Two potentially critical differences between these studies are that in Remmerwaal et al. (2013), but not Muris et al. (2010) or Remmerswaal et al. (2010): (a) parents were not given explicit instructions to communicate particular information to their child, which may have meant that the extent to which parents did express negative or positive information was lower than in those studies where this instruction was explicit; and (b) children were encouraged to engage in a task that involved confronting the novel animals rather than just thinking about them. This setup may have caused the children (including those in the negative information condition) to believe that the animals were not truly dangerous (i.e., that they would not be asked to do something that would cause them harm), yet still induced enough fear/doubt to influence their behavior. Variation in the context in which parental verbal communication was measured may also account for seemingly inconsistent findings regarding parents' use of negative emotion words. Specifically, Hosey \& Woodruff-Borden (2012) examined parents' use of negative emotion words whilst their child engaged in a challenging task and found a significant positive association between negative emotion words and child anxiety disorder status, whereas Suveg et al. (2005) used parent-child discussions about the child's past experience and found no significant association. 
To begin to overcome the problems illustrated above, future research should strive to evaluate associations between different features of parental verbal communication and child anxiety in a predetermined and systematic way. In the case of threat-related verbal communication, for example, researchers may wish to systematically evaluate associations between child anxiety and parental language that (a) initiates themes of threat (versus other, for example, positive themes), (b) develops themes of threat, and (c) develops topics in general. It will also be important that studies evaluate both the absolute amount of parental verbalisations of a particular kind and verbalisations that are specifically responses to children's anxious utterances (i.e., to consider reciprocal interactions between parents and children). To best ensure that the verbal communication features of interest are relatively free from contamination by other types of verbal communication it is recommended that existing experimental paradigms are utilised, in which parents are instructed as to how to communicate with their child under controlled conditions (e.g., Muris et al., 2010). Such designs will also be useful for investigating the effects of other variables, such as the source of information (e.g., mother vs. father) or the characteristics of the child (e.g., child $v s$. adolescent), as well as for looking at interactions between specific features of parental verbal communication. Although these experimental investigations may lack ecological validity, studies of social referencing and child anxiety provide a useful model of how experimental studies can be combined with, potentially more ecologically valid, longitudinal studies to inform theory relating to the development of anxiety in children. For example, in the Reading Longitudinal Study, de Rosnay, Cooper, Tsigaras, and Murray (2006) trained a community sample of mothers of 12-14 month old infants to behave in a non-anxious or a socially anxious way whilst their infant observed them interacting with a stranger, and found that mothers' modelling of anxious versus non-anxious responses to the stranger determined infants' later fearfulness to the same unfamiliar person. This was followed up by observing interactions between mothers with and without social phobia and their infants when introduced to a stranger, and then conducting longitudinal examinations of the infants' responses to a stranger. As expected, mothers with social phobia expressed more anxiety whilst interacting with the stranger than non-anxious mothers, and increased maternal expressed anxiety predicted increased infant avoidance of a stranger at 14 months (Murray et al., 2008). A similar combination of experimental and prospective, naturalistic studies using overlapping methods and coding schemes is required to develop understanding of the relationship between parental verbal communication and child anxiety. 
Inconsistent theoretical grounding. Another critical source of variation across studies relates to the theories that have informed what features of parents' verbal communication were examined. For example, whereas some features of verbal communication (e.g., threatrelated) had clear links with developmental models of anxiety in children (e.g., Murray et al., 2009), other features (e.g., elaboration, explanatory language, and discouragement of emotion discussion) originate in the literature concerning child emotion socialization and affective meaning-making processes (for a review of this literature see Oppenheim, 2006).

Furthermore, the specific variables that were examined do not always appear to be a true reflection of the theoretically-driven features of verbal communication that they aimed to assess. For example, categorizing 'suggestions' as overly controlling statements is not consistent with the conceptualisation of such statements as facilitating children's mastery, or scaffolding support, particularly as used with younger children (Vygotsky, 1978). Similarly, the assumption that, for example, use of particular personal pronouns (i.e., second-person singular pronouns; Hosey \& Woodruff-Borden, 2012) reflects 'over control' seems unwarranted. Just consider, for example "Would you (second person singular pronoun) like some more cake?", and think about whether it is an instance of over control. While reliance on coding methods that simply count instances of individual words is attractive in terms of coding time, there is a risk that this approach will fail to clarify the exact nature of communication that may promote or prevent anxiety in children. Future research should strive to develop coding schemes that reflect valid measures of constructs that (a) are directly relevant to theories of the development and maintenance of child anxiety, and (b) draw on more general theory relating to the socialization of children's emotions. In particular, consistent with contemporary developmental models of anxiety in children (e.g., Murray et al., 2009), close attention should be paid to parental verbalizations that may promote cognitions regarding threat, vulnerability, and that reinforce avoidant behavior on the one hand (i.e., 'anxiogenic' verbalizations), and those that may promote autonomy on the other hand (i.e., 'encouraging' verbalizations).

\section{Inconsistent consideration of potential moderating variables. Another important} limitation of the reviewed studies is the inconsistent consideration of factors that might moderate the influence of parental verbal communication on childhood anxiety. In addition to the potential moderating effects of the sex of the parent and age of the child (discussed further below), evidence has emerged that the association between parental verbal 
communication and child anxiety may be influenced by both parental anxiety and certain temperamental characteristics of the child.

Parental anxiety. There is some evidence that the relationship between parental verbal communication and child anxiety varies as a function of parental anxiety. For example, Moore et al. (2004) found that parents' catastrophizing behavior was significantly associated with child anxiety disorder status but this was among dyads with non-anxious parents only, such that non-anxious parents (but not anxious parents) made more catastrophizing remarks if they had anxious versus non-anxious children. Similarly, Schrock and Woodruff-Borden (2010) found that non-anxious, but not anxious, parents made more negative remarks if they had anxious versus non-anxious children. These findings may suggest that there is a limited role of parental verbal communication in relation to child anxiety in families where parents are themselves highly anxious, for example, due to relatively greater influences of other risk factors for child anxiety in this context. Alternatively, these findings may suggest that in nonanxious parent families child anxiety in fact shapes parental verbal communication. Further investigation will be essential to clarify how parental anxiety and parental verbal communication may interact in relation to the development of child anxiety, for example, by taking a longitudinal approach in which to examine the relative ability of parental verbalizations, parental anxiety disorder status, and their interaction to predict changes in child anxiety over time.

Child characteristics. There is also some evidence that certain child characteristics may moderate the relationship between parental verbal communication and child anxiety. This hypothesis has been debated extensively elsewhere and, therefore, will not be discussed in detail here (Muris \& Field, 2010; Murray et al., 2009). However, the basic idea is that certain genetically/environmentally determined personality traits are associated with increased susceptibility to threat/negative information. For example, Murray et al. (2014) found that the association between the amount of threat information in parental narratives and child social phobia diagnosis was significant only for dyads in which children had earlier been identified as being securely attached. For insecurely attached children, the likelihood of them being diagnosed with social phobia was raised regardless of their parents' level of verbal threat communication. This pattern of findings raises the possibility that securely attached children may be more susceptible to the effects of verbal threat information provided by their parents than insecurely attached children, perhaps because they are more likely to 
rely on their parents as figures of trust and sources of reliable information. Interestingly, Murray et al. (2014) did not find significant moderating effects of child temperament (i.e., behavioral inhibition; BI) on the association between parental verbal communication and child social phobia (although moderation by BI did apply to the association between child negative social cognitions and teacher reports of child anxiety symptoms). While the generalizability of these findings is yet to be tested in other populations, it is clear that future studies should strive to consider the potential moderating role of relevant child characteristics, such as behavioral inhibition and attachment status, in order to enhance the theoretical and clinical applications of their findings.

Lack of data on the mechanisms of anxiety acquisition. Following Rachman's theory of fear acquisition (Rachman, 1977, 1991), contemporary models of childhood anxiety assume that children's fears develop, in part, due to the acquisition of anxious cognitions (such as a tendency to interpret ambiguous stimuli as threatening, beliefs about being unable to cope, and a bias towards avoidant solutions to manage perceived threat) from parents via the verbal information pathway (e.g., Field \& Lester, 2010; Murray et al., 2009). In support of these theories, there is evidence that the cognitions of anxious children and their parents are highly correlated (Barrett, Rapee, Dadds, \& Ryan, 1996; Creswell, O’Connor, \& Brewin, 2006; Creswell, Schniering, \& Rapee, 2005; Kortlander, Kendall, \& Panichelli-Mindel, 1997; Micco \& Ehrenreich, 2008) and that low levels of parental verbal encouragement to the child in discussions about potential social threat mediate the effect of maternal social phobia on child cognitions (Murray et al, 2014), which in turn have been shown to predict later child anxiety symptoms (Pass, Arteche, Cooper, Creswell, \& Murray, 2012). There remains, however, no direct examination of whether changes in child anxiety result from the effect of parental verbal communication on children's anxious cognitions. In the same way that future research should strive to examine factors that may moderate the parental verbal communication-child anxiety relationship, it should also aim to improve understanding of the mechanisms through which verbal communication influences potential changes in child anxiety. This is another example of where the application of experimental frameworks will be an invaluable starting point by manipulating parental verbal communication and examining whether changes in child anxiety are mediated by theoretically-indicated factors (e.g., child cognitive biases). A good example of this type of experimental research comes from Remmerswaal, Muris, and Huijding (2015), who demonstrated that parents could influence 
both the strategy that their children used to search for information about novel animals and their children's fear of the animals. Specifically, children whose parents had been trained to instruct them to search for negative information about the animals subsequently showed a negative information search bias, whereas children whose parents had been trained to instruct them to search for positive information subsequently showed a positive information search bias. Crucially, after seeking out information in accordance with their parents' instructions, children whose parents received negative training reported increased fear of the animals, whereas children whose parents received positive information reported decreased fears. This provides some support for the idea that the association between parental verbal communication (and/or other socialization processes such as anxious modelling) and child anxiety is mediated by child cognitive biases. Unfortunately, however, mother-child interactions were not coded in this study, so no conclusions can be drawn about the veracity of this mechanism. It is, therefore, strongly recommended that future studies employing the method of Remmerswaal et al. (2015) strive to directly observe and evaluate the interactions between parents and their children, including theoretically-informed aspects of parental verbal communication.

Representativeness of samples. A clear limitation of the reviewed studies was the homogeneity of samples. Studies typically employed samples that were predominantly Caucasian (range $=67.0-100 \%$ ), and none of the studies examined the association between parental verbal communication and child anxiety in families from different ethnic or cultural backgrounds. This is important as there is some evidence that parents from different ethnic or cultural backgrounds verbally communicate with their children in different ways. For example, Wang and Fivush (2005) reported significant differences between Euro-American and Chinese parents in terms of the amount of negative emotion words they used during discussions with their child about the child's past experience (i.e., Chinese parents used more negative emotion words than did Euro-American parents). Furthermore, concepts such as 'control' may hold different meanings for families from different ethnic or cultural backgrounds (e.g., parental overinvolvement vs. parental concern) (Wood et al., 2003). Due to an over-reliance on predominantly Caucasian samples, it is unclear whether the findings of the reviewed studies apply to families from different ethic or cultural backgrounds. It is clear, therefore, that future research should endeavour to recruit diverse samples that will allow the examination of the effects of ethnicity and culture on the relationship between parental verbal 
communication and anxiety in children.

As well as being predominantly Caucasian, most studies employed parent samples that mainly consisted of mothers. Again, this is important, as the relationship between parental verbal communication and child anxiety may vary as a function of the sex of the parent. For instance, in Dadds et al. (1996), mothers of children with an anxiety disorder made fewer references to positive consequences than mothers of healthy children, whereas this effect was not observed for fathers. There is also growing evidence that the role fathers play in the development of childhood anxiety may be different from the role played by mothers (Bögels \& Phares, 2008; Majdandžić, Möller, de Vente, Bögels, \& van den Boom, 2014; Möller, Majdandžić, \& Bögels, 2014). For example, Majdandžić et al. (2014) reported that increases in fathers' challenging behavior during interactions with their 2-year-old children (e.g., encouraging the child to exceed his/her comfort zone) predicted decreases in children's social anxiety over the following 2 years, whereas increases in mothers' challenging behavior predicted increases in children's anxiety. Given the overwhelming focus on mothers in the reviewed studies, it is unclear whether the findings apply to fathers in the same way. Accordingly, there is a clear need not only to involve fathers in research on the association between parental verbal communication and child anxiety, but also to ensure that associations are examined separately for mothers and fathers. Such a shift is particularly urgent given the increasing role that fathers play in early years care (Sayer, Bianchi, \& Robinson, 2004).

Most studies employed child samples from a similar age range (i.e., $\approx 7-14$ years) (see Murray et al., 2014 and Schrock \& Woodruff-Borden, 2010 for exceptions). As a result, there is a scarcity of evidence regarding both younger children (i.e., $<7$ years) and adolescents, which limits the generalizability of the findings beyond the age group typically studied. Furthermore, just one study (i.e., Suveg et al., 2005) directly examined the effect of child age on the association between parental verbal communication and child anxiety, with the result being non-significant. Given the lack of evidence regarding younger children and adolescents, future studies should aim to recruit children who are of a broader age range than has been the case to date and to take age in to account in analyses. Not only will this improve the generalizability of findings, it will also allow the exploration of possible developmental effects when considering the role of parental verbal communication in the development and maintenance of child anxiety. This is important, as there are substantial normative shifts in parent-offspring interactions throughout development, with, for example, increases in the 
intensity of conflict and decreases in affectionate behaviors as children move in to adolescence (Eberly \& Montemayor, 1999; Laursen, Coy, \& Collins, 1998). Also, when parental behaviors and offspring anxiety disorder status have been compared between children and adolescents, the nature of the association has differed significantly. Specifically, parents of adolescents with anxiety disorders have been shown to exhibit more intrusiveness and lower warm engagement than parents of non-anxious adolescents, with the reverse pattern being found among children (Waite \& Creswell, 2015).

Reliance on self- and/or parent-report measures. Another limitation is that nearly one third of the reviewed studies relied exclusively upon self- or parent-reports of child anxiety. While such measures have several practical advantages (e.g., they can be administered quickly and at relatively low cost), additional assessment methods, such as behavioral observations, offer several interesting opportunities. For example, they offer the chance to collect data that are not confounded by children's or parents' potentially biased responses (e.g., due to parents' own anxious cognitive style), as well as the opportunity to collect anxiety data from younger children who may not be able to provide valid self-reports of their fears or anxieties. It is notable that in the one study that employed an observational measure of child anxiety (i.e., Remmerswaal et al., 2013), this measure appeared to be more sensitive to the influence of parents' negative verbal communication than the self-report measure used. It is suggested that a multidimensional approach for measuring child anxiety should be considered for future research.

\section{Reliance on aggregated or homogenous groupings of clinically anxious children.}

Studies of children with anxiety disorders in particular have suffered from two important limitations. First, just one of the reviewed studies recruited a clinical control group (Dadds et al., 1996). Consequently, there is little evidence to indicate whether features of parental verbal communication that have been shown to be associated with child anxiety disorder are associated with child anxiety in particular or child psychopathology in general. Second, all of the studies with children with anxiety disorders have either employed aggregated groupings of 'anxiety-disordered' children (i.e., they have not differentiated between children with different anxiety disorder diagnoses), or else they have used homogenous groupings of clinically anxious children diagnosed with the same anxiety disorder in the absence of a comparison group of children diagnosed with a different anxiety disorder. Given that there is growing evidence that the transmission of anxiety from parent to child occurs with a degree 
of specificity (Low, Cui, \& Merikangas, 2008; Murray et al., 2012), this limits the usefulness of the findings of the reviewed studies because disorder-specific effects may have been missed. For instance, it may be that parental verbalisations that emphasise embarrassment or shame are more closely related to social anxiety than to other types of anxiety in children, whereas verbalisations that emphasise abandonment or dependency may be more closely related to separation anxiety. Future research with children with anxiety disorders should consider including a non-anxious clinical control group and/or examining associations between parents' verbal communication to their child and different specific child anxiety disorders.

Reliance on cross-sectional designs. Beyond the three studies with non-clinical children that employed experimental designs (i.e., Muris et al., 2010 and Remmerswaal et al., 2010, 2013), nearly all the reviewed studies exclusively examined cross-sectional associations between parental verbal communication and child anxiety (see Murray et al., 2014 for an exception). While cross-sectional designs are useful for establishing the presence of straightforward relationships between parental verbal communication and child anxiety, such designs cannot reveal the direction of effects. That is, where significant effects were reported in cross-sectional studies, it cannot be established whether parental verbal communication affected child anxiety, child anxiety shaped parental verbal communication, or if there were reciprocal effects. This issue of directionality is crucial, as contemporary theoretical models predict that parental verbal communication is implicated in both the development and maintenance of childhood anxiety (e.g., Murray et al., 2009). In the absence of adequate empirical data elucidating the direction of effects, the extent to which the findings of the reviewed studies can be used to refine theoretical accounts of childhood anxiety (e.g., elucidate the causal and/or maintaining role of parental verbal communication) or inform clinical work (e.g., preventive and/or therapeutic interventions) is greatly limited. However, it is notable that in the experimental studies with non-clinical children, certain features of parental verbal communication (i.e., negative/threat statements) were associated with increases in children's fears following discussions with parents (e.g., Muris et al., 2010), suggesting that parental verbal communication may be involved in the development of anxiety in childhood. Consistent with this hypothesis, in the only study to have taken a developmental approach, children whose parents showed high levels of threat attribution during parent-child discussions were significantly more likely to be diagnosed with social 
phobia several months after the discussions took place as compared to children whose parents showed low levels of threat attribution (Murray et al., 2014). On the basis of these findings, it could tentatively be suggested that preventive interventions for child anxiety might usefully target anxiogenic aspects of parental verbal communication. Furthermore the development of screening tools to measure the verbal communication style of parents of 'at-risk' children (i.e., parents who themselves are highly anxious) might facilitate the identification of families most likely to benefit from this sort of intervention. Further investigation will be needed to provide clear guidance on the focus of interventions and screening tools, specifically to provide information on what features of parental verbal communication should be targeted, when expressed by which parents (e.g., those with anxiety disorders vs. those without anxiety disorders), with which children (e.g., securely vs. insecurely attached), and in which contexts (e.g., discussions about emotions vs. discussions about other topics).

\section{Limitations of the Review}

It is important to acknowledge that no search strategy can guarantee identification of all relevant literature. It is, therefore, possible that we failed to identify some potentially relevant evidence. On the one hand, given the pervasiveness of the methodological problems that we have discussed, it is questionable whether such oversights - assuming there were only one or two - would have substantially altered our conclusions (or lack thereof as the case may be). On the other hand, the implications of more substantial omissions due, for example, to publication bias, warrant further consideration. Due to the fairly small number of studies included in the review ( $n=15)$, unpublished studies could potentially have a sizeable impact on the broad interpretation of the findings presented here, as well as on the resultant suggestions for future research.

\section{Summary}

The aim of this review was to identify and evaluate the empirical literature on the association between observations of parents' verbal communication to their child and child anxiety. The results of the review - which included a relatively small number of studies despite reflecting nearly 20 years of research - provided preliminary evidence that certain types of parental verbal communication (i.e., threat-related, otherwise negative, controlling, positive, and general features) are associated with child anxiety under certain conditions. Overall, however, the results regarding various types of parental verbal communication were 
mixed. This is not surprising given that the existing body of research comprises a heterogeneous group of studies that have varied greatly in terms of their methodology. In particular, there was extensive variation in the features of parental verbal communication measured and the context in which this took place. There was also variation in studies' theoretical grounding, as well as inconsistent consideration of factors that may moderate the verbal communication-child anxiety relationship (e.g., parental anxiety, child attachment). Notably, no study directly examined the mechanisms through which parental verbal communication may influence child anxiety. In addition, the use of non-representative samples has considerably limited the generalizability of findings, while an over-reliance on cross-sectional designs has precluded establishing the direction of effects (i.e., parent-to-child vs. child-to-parent). 


\section{Statement of Conflict of Interest}

Funding: CC is funded by an NIHR Research Professorship (RP-2014-04-018).

Conflict of Interest: CC has grant funding from the NIHR and ESRC. There are no other potential conflicts of interest. 


\section{References}

Bandura, A. (1986). Social foundations of thought and action: A social cognitive theory. New Jersey: Prentice-Hall.

Barrett, P. M., Rapee, R. M., Dadds, M. M., \& Ryan, S. M. (1996). Family enhancement of cognitive style in anxious and aggressive children. Journal of Abnormal Child Psychology. 24 (2), 187-203. doi: 10.1007/BF01441484

Beidel, D. C. \& Turner, S. M. (1997). At risk for anxiety: I. Psychopathology in the offspring of anxious parents. Journal of the American Academy of Child \& Adolescent Psychiatry, 36 (7), 918-924. doi: 10.1097/00004583-199707000-00013

Bittner, A., Egger, H. L., Erkanli, A., Costello, E. J., Foley, D. L., \& Angold, A. (2007). What do childhood anxiety disorders predict? Journal of Child Psychology and Psychiatry, 48 (12), 1174-1183. doi: 10.1111/j.1469-7610.2007.01812.x

Bögels, S. \& Phares, V. (2008). Fathers' role in the etiology, prevention and treatment of child anxiety: A review and new model. Clinical Psychology Review, 28 (4), 539-558. doi: 10.1016/j.cpr.2007.07.011

Brumariu, L. E., \& Kerns, K. A. (2015). Mother-child emotion communication and childhood anxiety symptoms. Cognition and Emotion, 29 (3), 416-431. doi: $10.1080 / 02699931.2014 .917070$

Cohen, J. (1988). Statistical power analysis for the behavioral sciences (2nd ed.). New York: Lawrence Erlbaum Associates.

Comer, J. S., Blanco, C., Hasin, D. S., Liu, S. M., Grant, B. F., Turner, J. B., \& Olfson, M. (2011). Health-related quality of life across the anxiety disorders: Results from the national epidemiologic survey on alcohol and related conditions (NESARC). Journal of Clinical Psychiatry, 72(1), 43-50. doi: 10.4088/JCP.09m05094blu

Cooper, P. J., Fearn, V., Willetts, L., Seabrook, H., \& Parkinson, M. (2006). Affective disorder in the parents of a clinic sample of children with anxiety disorders. Journal of Affective Disorders, 93 (1), 205-212. doi: 10.1016/j.jad.2006.03.017 
Costello, E. J., Egger, H. L., Copeland, W., Erkanli, A., \& Angold, A. (2011). The developmental epidemiology of anxiety disorders: Phenomenology, prevalence, and comorbidity. In W. K. Silvermanm \& A. P. Field (Eds.), Anxiety disorders in children and adolescents: Research, assessment and intervention (pp. 56-75). Cambridge: Cambridge University Press.

Creswell, C., O’Connor, T. G., \& Brewin, C. R. (2006). A longitudinal investigation of maternal and child 'anxious cognitions'. Cognitive Therapy and Research, 30 (2), 135147. doi: 10.1007/s10608-006-9021-1

Creswell, C., Schniering, C. A., \& Rapee, R. M. (2005). Threat interpretation in anxious children and their mothers: Comparison with nonclinical children and the effects of treatment. Behaviour Research and Therapy, 43 (10), 1375-1381. doi: 10.1016/j.brat.2004.10.009

Dadds, M. R., Barrett, P. M., Rapee, R. M., \& Ryan, S. (1996). Family process and child anxiety and aggression: An observational analysis. Journal of Abnormal Child Psychology, 24 (6), 715-734. doi: 10.1007/BF01664736

De Rosnay, M., Cooper, P. J., Tsigaras, N., \& Murray, L. (2006). Transmission of social anxiety from mother to infant: An experimental study using a social referencing paradigm. Behaviour Research and Therapy, 44 (8), 1165-1175. doi: 10.1016/j.brat.2005.09.003

Denham, S. A., Zoller, D., \& Couchoud, E. A. (1994). Socialization of preschoolers' emotion understanding. Developmental Psychology, 30 (6), 928-936. doi: 10.1037/00121649.30.6.928

Dunn, J., Bretherton, I., \& Munn, I. (1987). Conversations about feeling states between mothers and their young children. Developmental Psychology, 23 (1), 132-139. doi: $10.1037 / 0012-1649.23 .1 .132$

Dunn, J., Brown, J., \& Beardsall, L. (1991). Family talk about feeling states and their children's later understanding of others' emotions. Developmental Psychology, 27 (3), 448-455. doi: 10.1037/0012-1649.27.3.448 
Eberly, M. B. \& Montemayor, R. (1999). Adolescent affection and helpfulness toward parents: A 2-year follow-up. The Journal of Early Adolescence, 19 (2), 226-248. doi: $10.1177 / 0272431699019002005$

Egger, H. L. \& Angold, A. (2006). Common emotional and behavioral disorders in preschool children: Presentation, nosology, and epidemiology. Journal of Child Psychology and Psychiatry, 47(3-4), 313-337. doi: 10.1111/j.1469-7610.2006.01618.x

Field, A. H. \& Lawson, J. (2003). Fear information and the development of fears during childhood: Effects on implicit fear responses and behavioural avoidance. Behaviour Research and Therapy, 41 (11), 1277-1293. doi: 10.1016/S0005-7967(03)00034-2

Field, A. P. (2006). Is conditioning a useful framework for understanding the development and treatment of phobias? Clinical Psychology Review, 26 (7), 857-875. doi: 10.1016/j.cpr.2005.05.010

Field, A. P., \& Lester, K. J. (2010). Learning of information processing biases in anxious children and adolescents. In J. Hadwin \& A. P. Field (Eds.), Information processing biases and anxiety: A developmental perspective. Chichester: Wiley.

Field, A. P., Argyris, N. G., \& Knowles, K. A. (2001). Who's afraid of the big bad wolf: A prospective paradigm to test Rachman's indirect pathways in children. Behaviour Research and Therapy, 39 (11), 1259-1276. doi: 10.1016/S0005-7967(00)00080-2

Field, A. P., Hamilton, S. J., Knowles, K. A., \& Plews, E. L. (2003). Fear information and social phobic beliefs in children: A prospective paradigm and preliminary results. Behaviour Research and Therapy, 41 (1), 113-123. doi: 10.1016/S00057967(02)00050-5

Field, A., Lawson, J., \& Banerjee, R. (2008). The verbal threat information pathway to fear in children: The longitudinal effects on fear cognitions and the immediate effects on avoidance behavior. Journal of Abnormal Psychology, 117(1), 214-224. doi: 10.1037/0021-843X.117.1.214 
Fisak Jr, B. \& Grills-Taquechel, A. E. (2007). Parental modeling, reinforcement, and information transfer: Risk factors in the development of child anxiety? Clinical Child and Family Psychology Review, 10 (3), 213-231. doi: 10.1007/s10567-007-0020-x

Fivush, R. \& Nelson, K. (2006). Parent-child reminiscing locates the self in the past. British Journal of Developmental Psychology, 24 (1), 235-251. doi: $10.1348 / 026151005 \times 57747$

Fivush, R., Haden, C., \& Reese, E. (2006). Elaborating on elaborations: Role of maternal reminiscing style in cognitive and social emotional development. Child Development, 77 (6), 1568-1588. doi: 10.1111/j.1467-8624.2006.00960.x

Ford, T., Goodman, R., \& Meltzer, H. (2003). The British child and adolescent mental health survey 1999: The prevalence of DSM-IV disorders. Journal of the American Academy of Child \& Adolescent Psychiatry, 42 (10), 1203-1211. doi:10.1097/00004583200310000-00011

Francis, G. \& Grubb, J. (1987). Psychiatric illness in the mothers of anxious children. American Journal of Psychiatry, 144 (12), 1580-1583.

Gregory, A. M. \& Eley, T. (2007). Genetic influences on anxiety in children: What we've learned and where we're heading. Clinical Child and Family Psychology, 10 (3), 199212. doi: 10.1007/s10567-007-0022-8

Hane, A. A. \& Barrios, E. S. (2011). Mother and child interpretations of threat in ambiguous situations: Relations with child anxiety and autonomic responding. Journal of Family Psychology, 25 (5), 644-652. doi: 10.1037/a0024149

Hettema, J. M., Neale, M. C., \& Kendler, K. S. (2001). A review and meta-analysis of the genetic epidemiology of anxiety disorders. American Journal of Psychiatry, 158 (10), 1568-1578. doi: 10.1176/appi.ajp.158.10.1568

Hosey, R. P. \& Woodruff-Borden, J. (2012). An examination of the relationship between parent language and child anxiety. Child and Family Behavior Therapy, 34 (3), 210230. doi: 10.1080/07317107.2012.707089 
Hudson, J. L. \& Rapee, R. M. (2004). From anxious temperament to disorder: An etiological model. In R. G. Heimberg, C. L. Turk, \& D. S. Mennin (Eds), Generalized Anxiety Disorder: Advances in research and practice (pp. 51-75). New York: Guilford Press.

Hughes, A. A., Lourea-Waddell, B., \& Kendall, P. C. (2008). Somatic complaints in children with anxiety disorders and their unique prediction of poorer academic performance. Child Psychiatry and Human Development, 39(2), 211-220. doi: 10.1007/s10578-007$0082-5$

Hummel, R. M. \& Gross, A. M. (2001). Socially anxious children: An observational study of parent-child interaction. Child and Family Behavior Therapy, 23 (3), 19-40. doi: 10.1300/J019v23n03_02

Kessler, R. C. \& Frank, R. G. (1997). The impact of psychiatric disorders on work loss days. Psychological Medicine, 27(4), 861-873. doi: 10.1017/S0033291797004807

Kessler, R. C., Borges, G., \& Walters, E. E. (1999). Prevalence of and risk factors for lifetime suicide attempts in the National Comorbidity Survey. Archives of General Psychiatry, 56(7), 617-626. doi: 10.1001/archpsyc.56.7.617

Kortlander, E., Kendall, P. C., \& Panichelli-Mindel, S. M. (1997). Maternal expectations and attributions about coping in anxious children. Journal of Anxiety Disorders, 11 (3), 297-315. doi: 10.1016/S0887-6185(97)00012-1

Lang, P. J. (1968). Fear reduction and fear behavior: Problems in treating a construct. In J. M. Schlien (Ed.), Research in psychotherapy (Vol. 3, pp. 90-103). Washington, DC: American Psychological Association.

Lang, P. J. (1985). The cognitive psychopathology of emotion: Fear and anxiety. In A. H. Tuma \& J. D. Maser (Eds.), Anxiety and the anxiety disorders (pp. 131-170). Hillsdale, NJ: Erlbaum.

Laursen, B., Coy, K. C., \& Collins, W. A. (1998). Reconsidering changes in parent-child conflict across adolescence: A meta-analysis. Child Development, 69 (3), 817-832. doi: 10.1111/j.1467-8624.1998.tb06245.x 
Lavigne, J. V., Gibbons, R. D., Christoffel, K. K., Arend, R., Rosenbaum, D., Binns, H., ... \& Isaacs, C. (1996). Prevalence rates and correlates of psychiatric disorders among preschool children. Journal of the American Academy of Child \& Adolescent Psychiatry, 35(2), 204-214. doi: 10.1097/00004583-199602000-00014

Lawson, J., Banerjee, R., \& Field, A. P. (2007). The effects of verbal information on children's fear beliefs about social situations. Behaviour Research and Therapy, 45 (1), 21-37. doi: 10.1016/j.brat.2006.01.007

Lieb, R., Wittchen, H. U., Höfler, M., Fuetsch, M., Stein, M. B., \& Merikangas, K. R. (2000). Parental psychopathology, parenting styles, and the risk of social phobia in offspring: a prospective-longitudinal community study. Archives of General Psychiatry, 57 (9), 859-866. doi: 10.1001/archpsyc.57.9.859

Low, N. C., Cui, L., \& Merikangas, K. R. (2008). Specificity of familial transmission of anxiety and comorbid disorders. Journal of Psychiatric Research, 42 (7), 596-604. doi: 10.1016/j.jpsychires.2007.07.002

Majdandžić, M., Möller, E. L., de Vente, W., Bögels, S. M., \& van den Boom, D. C. (2014). Fathers' challenging parenting behavior prevents social anxiety development in their 4year-old children: A longitudinal observational study. Journal of Abnormal Child Psychology, 42 (2), 301-310. doi: 10.1007/s10802-013-9774-4

McLeod, B. D., Wood, J. J., \& Weisz, J. R. (2007). Examining the association between parenting and childhood anxiety: A meta-analysis. Clinical Psychology Review, 27 (2), 155-172. doi: 10.1016/j.cpr.2006.09.002

Merckelbach, H., De Jong, P. J., Muris, P., \& Van den Hout, M. A. (1996a). The etiology of specific phobias: A review. Clinical Psychology Review, 16 (4), 337-361. doi: 10.1016/0272-7358(96)00014-1

Micco, J. A. \& Ehrenreich, J. T. (2008). Children's interpretation and avoidant response biases in response to non-salient and salient situations: Relationships with mothers' threat perception and coping expectations. Journal of Anxiety Disorders, 22 (3), 371385. doi: 10.1016/j.janxdis.2007.03.009 
Möller, E. L., Majdandžić, M., \& Bögels, S. M. (2014). Parental Anxiety, Parenting Behavior, and Infant Anxiety: Differential Associations for Fathers and Mothers. Journal of Child and Family Studies, 1-12. doi: 10.1007/s10826-014-0065-7

Moore, P. S., Whaley, S. E., \& Sigman, M. (2004). Interactions between mothers and children: impacts of maternal and child anxiety. Journal of Abnormal Psychology, 113 (3), 471-476. doi: 10.1037/0021-843X.113.3.471

Muris, P. \& Field, A. P. (2010). The role of verbal threat information in the development of childhood fear."Beware the Jabberwock!". Clinical Child and Family Psychology Review, 13 (2), 129-150. doi: 10.1007/s10567-010-0064-1

Muris, P., van Zwol, L., Huijding, J., \& Mayer, B. (2010). Mom told me scary things about this animal: Parents installing fear beliefs in their children via the verbal information pathway. Behaviour Research and Therapy, 48 (4), 341-346. doi: 10.1016/j.brat.2009.12.001

Murray, L., Creswell, C., \& Cooper, P. J. (2009). The development of anxiety disorders in childhood: An integrative review. Psychological Medicine, 39 (9), 1413-1423. doi: $10.1017 / \mathrm{S} 0033291709005157$

Murray, L., De Rosnay, M., Pearson, J., Bergeron, C., Schofield, E., Royal-Lawson, M., \& Cooper, P. J. (2008). Intergenerational transmission of social anxiety: The role of social referencing processes in infancy. Child Development, 79 (4), 1049-1064. doi: 10.1111/j.1467-8624.2008.01175.x

Murray, L., Lau, P. Y., Arteche, A., Creswell, C., Russ, S., Zoppa, L. D., ... \& Cooper, P. (2012). Parenting by anxious mothers: Effects of disorder subtype, context and child characteristics. Journal of Child Psychology and Psychiatry, 53(2), 188-196. doi: 10.1111/j.1469-7610.2011.02473.x

Murray, L., Pella, J. E., De Pascalis, L. D., Arteche, A., Pass, L., Percy., R., Creswell, C., \& Cooper, P. J. (2014). Socially anxious mothers' narratives to their children, and their relation to child representations and adjustment. Development and Psychopathology, 26, 1531-1546. 
Oppenheim, D. (2006). Child, parent, and parent-child emotion narratives: Implications for developmental psychopathology. Development and Psychopathology, 18(3), 771-790. doi: 10.1017/S095457940606038X

Pass, L., Arteche, A., Cooper, P., Creswell, C., \& Murray, L. (2012). Doll Play narratives about starting school in children of socially anxious mothers, and their relation to subsequent child school-based anxiety. Journal of Abnormal Child Psychology, 40 (8), 1375-1384. doi: 10.1007/s10802-012-9645-4

Rachman, S. (1977). The conditioning theory of fear-acquisition: A critical examination. Behaviour Research and Therapy, 15 (5), 375-387. doi: 10.1016/0005-7967(77)900419

Rachman, S. (1991). Neo-conditioning and the classical theory of fear acquisition. Clinical Psychology Review, 11 (2), 155-173. doi: 10.1016/0272-7358(91)90093-A

Raikes, H. A. \& Thompson, R. A. (2006). Family emotional climate, attachment security and young children's emotion knowledge in a high risk sample. British Journal of Developmental Psychology, 24, 89-104. doi: 10.1348/026151005X70427

Ramsawh, H. J., Weisberg, R. B., Dyck, I., Stout, R., \& Keller, M. B. (2011). Age of onset, clinical characteristics, and 15-year course of anxiety disorders in a prospective, longitudinal, observational study. Journal of Affective Disorders, 132(1), 260-264. doi: 10.1016/j.jad.2011.01.006

Rapee, R. M. (2012). Family factors in the development and management of anxiety disorders. Clinical Child and Family Psychology Review, 15 (1), 69-80. doi: 10.1007/s10567-011-0106-3

Remmerswaal, D., Muris, P., \& Huijding, J. (2013). "Watch out for the gerbils, my child!" The role of maternal information on children's fear in an experimental setting using real animals. Behavior Therapy, 44( 2), 317-324. doi: 10.1016/j.beth.2013.01.001

Remmerswaal, D., Muris, P., \& Huijding, J. (2015). Transmission of Cognitive Bias and Fear From Parents to Children: An Experimental Study. Journal of Clinical Child and Adolescent Psychology, 53, 1-13. doi: 10.1080/15374416.2014.987378 
Remmerswaal, D., Muris, P., Mayer, B., \& Smeets, G. (2010). "Will a Cuscus bite you, if he shows his teeth?" Inducing a fear-related confirmation bias in children by providing verbal threat information to their mothers. Journal of Anxiety Disorders, 24 (5), 540546. doi: 10.1016/j.janxdis.2010.03.012

Rubin, K. H., Coplan, R. J., \& Bowker, J. C. (2009). Social withdrawal in childhood. Annual Review of Psychology, 60, 141-171. doi: 10.1146/annurev.psych.60.110707.163642

Ruffman, T., Slade, L., Devitt, K., \& Crowe, E. (2006). What mothers say and what they do: The relation between parenting, theory of mind, language and conflict/cooperation. British Journal of Developmental Psychology, 24 (1), 105-124. doi: $10.1348 / 026151005 X 82848$

Sales, J. M. Fivush, R. (2005). Social and emotional functions of mother-child reminiscing about stressful events. Social Cognition, 23 (1), 70 - 90. doi: $10.1521 /$ soco.23.1.70.59196

Sayer, L. C., Bianchi, S. M., \& Robinson, J. P. (2004). Are parents investing less in children? Trends in mothers' and fathers' time with children. American Journal of Sociology, 110 (1), 1-43. doi: $10.1086 / 386270$

Schrock, M. \& Woodruff-Borden, J. (2010). Parent-child interactions in anxious families. Child and Family Behavior Therapy, 32 (4), 291-310. doi: $10.1080 / 07317107.2010 .515523$

Silverman, W. K., \& Albano, A. M. (1996). The anxiety disorders interview schedule for children for DSM-IV: Child and parent versions. San Antonio: Psychological Corporation.

Spence, S. H., Najman, J. M., Bor, W., O'Callaghan, M. J., \& Williams, G. M. (2002). Maternal anxiety and depression, poverty and marital relationship factors during early childhood as predictors of anxiety and depressive symptoms in adolescence. Journal of Child Psychology and Psychiatry, 43(4), 457-469. doi: 10.1111/1469-7610.00037 
Suveg, C., Sood, E., Barmish, A., Tiwari, S., Hudson, J. L., \& Kendall, P. C. (2008). "I'd rather not talk about it": Emotion parenting in families of children with an anxiety disorder. Journal of Family Psychology, 22 (6), 875-884. doi: 10.1037/a0012861

Suveg, C., Zeman, J., Flannery-Schroeder, E., \& Cassano, M. (2005). Emotion socialization in families of children with an anxiety disorder. Journal of Abnormal Child Psychology, 33 (2), 145-155. doi: 10.1007/s10802-005-1823-1

Taber, S. M. (2010). The veridicality of children's reports of parenting: A review of factors contributing to parent-child discrepancies. Clinical Psychology Review, 30 (8), 9991010. doi: 10.1016/j.cpr.2010.06.014

Taumoepeau, M. \& Ruffman, T. (2008). Stepping stones to others' minds: Maternal talk relates to child mental state language and emotion understanding at 15, 24, and 33 months. Child Development, 79 (2), 284 - 302. doi: 10.1111/j.1467-8624.2007.01126.x

Turner, S. M., Beidel, D. C., Roberson-Nay, R., \& Tervo, K. (2003). Parenting behaviors in parents with anxiety disorders. Behaviour Research and Therapy, 41 (5), 541-554. doi: 10.1016/S0005-7967(02)00028-1

Vygotsky, L.S. (1978). Mind in society: The development of higher psychological processes. Cambridge, MA: Harvard University Press

Waite, P. \& Creswell, C. (2015). Observing interactions between children and adolescents and their parents: The effects of anxiety disorder and age. Journal of Abnormal Child Psychology, 1-13. doi: 10.1007/s10802-015-0005-z

Wang, Q. \& Fivush, R. (2005). Mother-child conversations of emotionally salient events: Exploring the function of emotional reminiscing in European-American and Chinese families. Social Development, 14 (3), 473 - 495. doi: 10.1111/j.14679507.2005.00312.x

Whaley, S. E., Pinto, A., \& Sigman, M. (1999). Characterizing interactions between anxious mothers and their children. Journal of Consulting and Clinical Psychology, 67 (6), 826836. doi: 10.1037/0022-006X.67.6.826 
Wichstrøm, L., Berg-Nielsen, T. S., Angold, A., Egger, H. L., Solheim, E., \& Sveen, T. H. (2012). Prevalence of psychiatric disorders in preschoolers. Journal of Child Psychology and Psychiatry, 53(6), 695-705. doi: 10.1111/j.1469-7610.2011.02514.x

Wood, J. J., McLeod, B. D., Sigman, M., Hwang, W-C., \& Chu, B. C. (2003). Parenting and childhood anxiety: Theory, empirical findings, and future directions. Journal of Child Psychology and Psychiatry, 44 (1), 134-151. doi: 10.1111/1469-7610.00106

Woodward, L. J. \& Fergusson, D. M. (2001). Life course outcomes of young people with anxiety disorders in adolescence. Journal of the American Academy of Child and Adolescent Psychiatry, 40 (9), 1086-1093. 
Figure 1

Search Procedure Flow Diagram

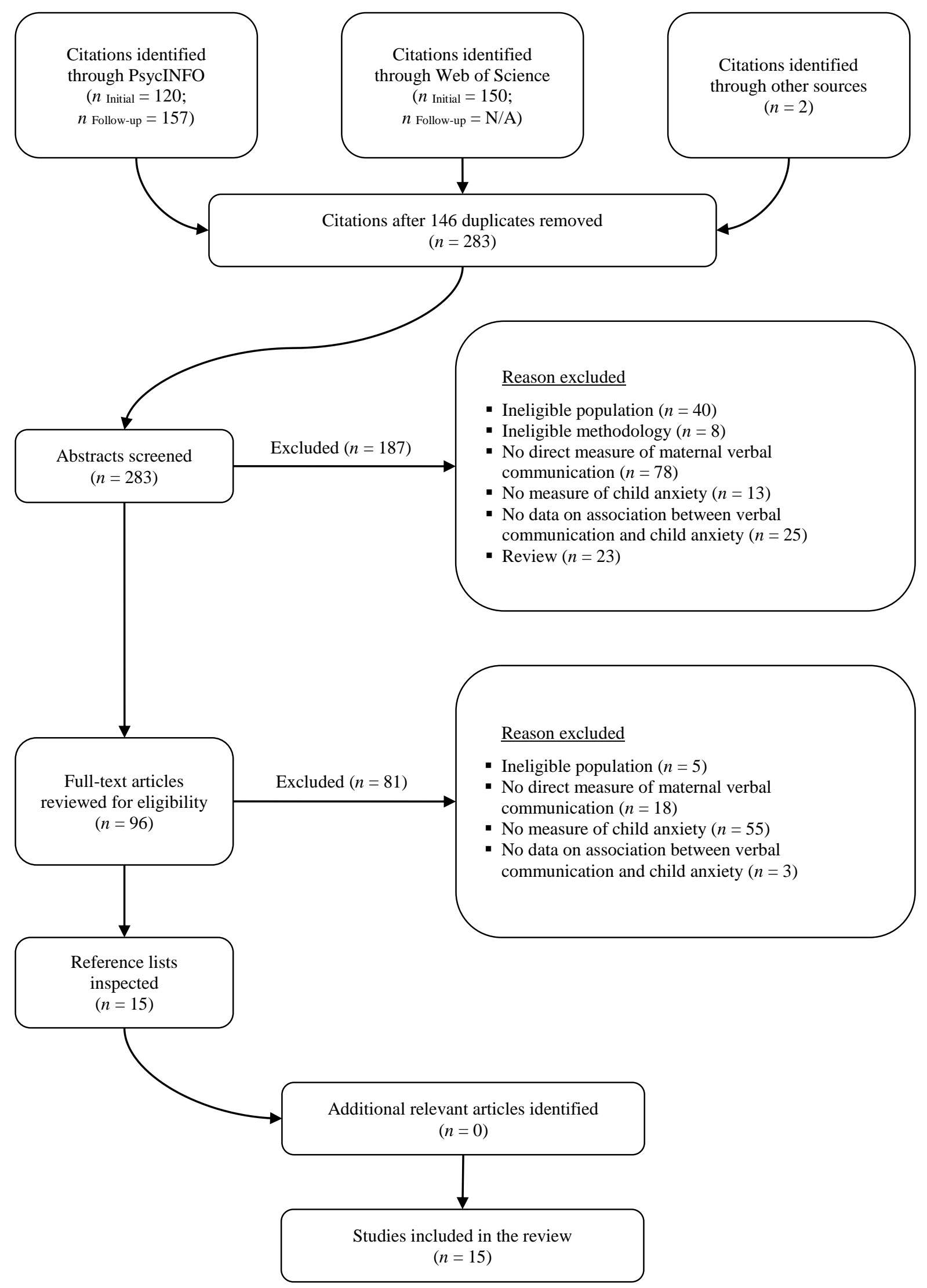


Table 1

Overview of the General and Sample Characteristics of the Reviewed Studies

\begin{tabular}{|c|c|c|c|c|c|c|c|c|c|c|c|c|}
\hline \multirow[b]{2}{*}{ Study } & \multicolumn{4}{|c|}{ General characteristics } & \multicolumn{4}{|c|}{ Child characteristics } & \multicolumn{3}{|c|}{ Parent characteristics } & \multirow[b]{2}{*}{$\begin{array}{l}\text { Ethnicity } \\
\text { (\% CAU) }\end{array}$} \\
\hline & Location & Setting & Design & $\begin{array}{l}\text { Recruitment } \\
\text { strategy }\end{array}$ & $N$ & $\begin{array}{l}\text { Sex } \\
(\% \text { female })\end{array}$ & $\begin{array}{l}\text { Age range } \\
\text { (years) }\end{array}$ & $\begin{array}{l}\text { Dx. } \\
\text { (\% anxious) }\end{array}$ & $N$ & $\begin{array}{l}\text { Sex } \\
(\% \text { mothers })\end{array}$ & $\begin{array}{l}\text { Mean age } \\
\text { (years) }\end{array}$ & \\
\hline Brumariu \& Kerns (2015) & US & $\bar{L}$ & $\bar{C}$ & $\mathrm{CC}, \mathrm{S}$ & 87 & 55.2 & $10-12$ & $4.6 \%$ & 87 & 100.0 & NR & 67.0 \\
\hline Dadds, Barrett, Rapee, \& Ryan (1996) & $\mathrm{AU}$ & $\mathrm{L}$ & $\mathrm{C}$ & $\mathrm{C}, \mathrm{CC}$ & 100 & 55.0 & $7-14$ & 66.0 & 168 & 58.3 & 38.9 & NR \\
\hline Hane \& Barrios (2011) & US & $\mathrm{L}$ & $\mathrm{C}$ & $\mathrm{S}$ & 35 & 40.0 & $8-10$ & NR & 35 & 100.0 & NR & 100.0 \\
\hline Hosey \& Woodruff-Borden (2012) & US & $\mathrm{L}$ & $\mathrm{C}$ & $\mathrm{C}, \mathrm{CC}$ & 154 & 53.9 & 3-12 & 39.6 & 154 & 92.2 & 36.0 & 75.3 \\
\hline Hummel \& Gross (2001) & US & $\mathrm{H}$ & $\mathrm{C}$ & $\mathrm{S}$ & 30 & 60.0 & $9-12$ & 50.0 & 60 & 50.0 & 42.1 & 93.0 \\
\hline Moore, Whaley, \& Sigman (2004) & US & $\mathrm{L}$ & $\mathrm{C}$ & $\mathrm{CA}, \mathrm{CC}$ & 68 & 48.5 & $7-15$ & 64.7 & 68 & 100.0 & NR & 79.40 \\
\hline Muris, van Zwol, Huijding, \& Mayer (2010) & NL & $\mathrm{L}, \mathrm{S}$ & $\mathrm{E}$ & $\mathrm{S}$ & 88 & 42.7 & $8-13$ & NR & 88 & 81.8 & 40.4 & $>80.0$ \\
\hline Murray et al. (2014) & UK & $\mathrm{L}$ & $\mathrm{L}$ & $\mathrm{C}$ & 136 & 68.4 & $4-5$ & 8.1 & 136 & 100.0 & 36.4 & 99.3 \\
\hline Remmerswaal, Muris, \& Huidjing (2013) & NL & $\mathrm{H}$ & $\mathrm{E}$ & $\mathrm{S}$ & 47 & 66.0 & $8-12$ & NR & 47 & 100.0 & 41.8 & 70.2 \\
\hline Remmerswaal, Muris, Mayer, \& Smeets (2010) & NL & $\mathrm{L}, \mathrm{S}$ & $\mathrm{E}$ & $\mathrm{S}$ & 52 & 51.9 & $9-12$ & NR & 52 & 100.0 & 42.9 & $>95.0$ \\
\hline Schrock \& Woodruff-Borden (2010) & US & $\mathrm{L}$ & $\mathrm{C}$ & $\mathrm{C}, \mathrm{CC}$ & 158 & 57.0 & $3-12$ & 38.0 & 158 & 92.4 & 36.2 & 76.1 \\
\hline Suveg et al. (2008) & US & $\mathrm{L}$ & $\mathrm{C}$ & $\mathrm{C}, \mathrm{CC}$ & 56 & 53.6 & $8-13$ & 50.0 & 112 & 50.00 & NR & 88.7 \\
\hline Suveg, Zeman, Flannery-Schroeder, \& Cassano (2005) & US & $\mathrm{L}$ & $\mathrm{C}$ & $\mathrm{S}$ & 52 & 53.9 & $8-12$ & 50.0 & 52 & 100.0 & 37.3 & NR \\
\hline Turner, Beidel, Roberson-Nay, \& Tervo (2003) & US & $\mathrm{L}$ & $\mathrm{C}$ & $\mathrm{C}, \mathrm{CA}$ & 81 & 53.6 & $7-12$ & 18.5 & 81 & 88.9 & 36.9 & 90.1 \\
\hline Whaley, Pinto, \& Sigman (1999) & US & $\mathrm{L}, \mathrm{H}$ & $\mathrm{C}$ & CA, $\mathrm{S}$ & 36 & 44.4 & $7-14$ & 33.3 & 36 & 100.0 & 41.9 & 77.8 \\
\hline
\end{tabular}

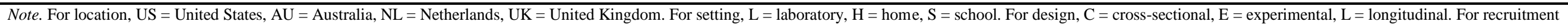
strategy, $\mathrm{S}=$ schools, $\mathrm{CC}=$ child clinics, $\mathrm{C}=$ community, $\mathrm{CA}=$ adult clinics. $\mathrm{Dx} .=$ diagnostic status. For ethnicity, $\mathrm{CAU}=\mathrm{Caucasian}, \mathrm{NR}=$ not reported. 
Overview of the Reviewed Studies' Approach to Measuring Parental Verbal Communication

\begin{tabular}{|c|c|c|c|c|c|}
\hline Study & Context & Verbal communication features measured & Strategy & Unit & Reliability \\
\hline Brumariu \& Kerns (2015) & $\mathrm{C}$ & Elaboration & CO (5-PS) & $\mathrm{C}$ & $\mathrm{k}=.73$ \\
\hline Dadds et al. (1996) & $\mathrm{V}$ & $\begin{array}{l}\text { Description (threat vs. non-threat), solution (pro-social vs. aggressive vs. avoidant), consequence (positive vs. negative), and response } \\
\text { (agreement vs. disagreement) }\end{array}$ & $\mathrm{CO}(\mathrm{FR})$ & SE & $\mathrm{k}=.61-.87$ \\
\hline Hane \& Barrios (2011) & $\mathrm{V}$ & Threat initiation, expansion, and minimisation & $\mathrm{CO}(\mathrm{RPM})$ & $\mathrm{U}$ & $\mathrm{k}=.61-.95$ \\
\hline $\begin{array}{l}\text { Hosey \& Woodruff-Borden } \\
\text { (2012) }\end{array}$ & $\mathrm{T}$ & First-person pronouns, first-person plural pronouns, second-person pronouns, negations, negative emotion words, and words of exclusion & $\mathrm{CO}(\mathrm{FR})$ & $\mathrm{W}$ & NR \\
\hline Hummel \& Gross (2001) & $\mathrm{T}$ & Command, suggestion, explanation, question, positive and negative feedback & $\mathrm{CO}(\mathrm{FR})$ & NR & $\mathrm{k}=.78-.92$ \\
\hline Moore et al. (2004) & {$[\mathrm{A}, \mathrm{C}]$} & Catastrophizing & $\mathrm{CA}$ & $\mathrm{C}$ & NR \\
\hline Muris et al. (2010) & $\mathrm{V}$ & Negative statements & $\mathrm{CO}(\mathrm{FR})$ & ST & $r=.97$ \\
\hline Murray et al. (2014) & $\mathrm{V}$ & Threat attribution & CA1 & $\mathrm{U}$ & $\mathrm{k}=.93-1.00$ \\
\hline Remmerswaal et al.(2013) & $\mathrm{T}$ & $\begin{array}{l}\text { Autonomy promotion } \\
\text { Negative and positive statements }\end{array}$ & $\begin{array}{l}\mathrm{CO}(\mathrm{FR}) \\
\mathrm{CO}(\mathrm{FR})\end{array}$ & $\begin{array}{l}\mathrm{U} \\
\mathrm{ST}\end{array}$ & NR \\
\hline Remmerswaal et al. (2010) & $\mathrm{V}$ & Negative statements & $\mathrm{CO}(\mathrm{FR})$ & ST & $r=.94$ \\
\hline $\begin{array}{l}\text { Schrock \& Woodruff-Borden } \\
\text { (2010) }\end{array}$ & $\mathrm{T}$ & Productive engagement, negative interaction, over-control & $\mathrm{CO}(\mathrm{FR})$ & $\mathrm{U}$ & $\mathrm{k}=.81-1.00$ \\
\hline Suveg et al. (2008) & $\mathrm{A}, \mathrm{An}, \mathrm{H}$ & Emotion words & $\mathrm{CO}(\mathrm{FR})$ & $\mathrm{W}$ & $r=.66-.99$ \\
\hline \multirow{3}{*}{ Suveg et al. (2005) } & \multirow{3}{*}[\mathrm{A},\mathrm{S},\mathrm{An}]{} & Emotion-related explanatory language and encouragement and discouragement of emotion & $\mathrm{CO}(5-\mathrm{PS})$ & NR & \\
\hline & & Positive and negative emotion words & $\mathrm{CO}(\mathrm{FR})$ & $\mathrm{W}$ & $\mathrm{k}=.63-1.00$ \\
\hline & & Emotion-related explanatory language and discouragement of emotion discussion & $\mathrm{CA}$ & NR & \\
\hline Turner et al. (2003) & $\mathrm{T}$ & Cautionary, directing. critical, and encouraging statements & $\mathrm{CO}(\mathrm{FR})$ & ST & $r=.74-.85$ \\
\hline Whaley et al. (1999) & {$[\mathrm{IP}, \mathrm{A}, \mathrm{C}]$} & Catastrophizing & $\mathrm{CO}(5-\mathrm{PS})$ & $\mathrm{C}$ & $r=.82$ \\
\hline
\end{tabular}

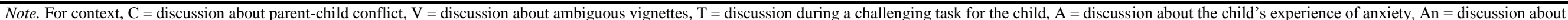

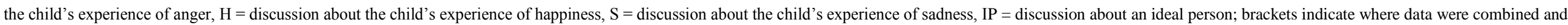

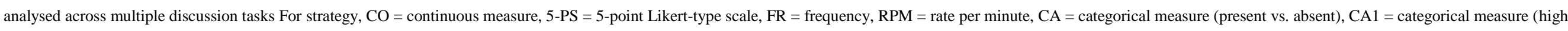
level vs. low level). For unit, $\mathrm{C}=$ whole conversation, $\mathrm{SE}=$ sentence, $\mathrm{U}=$ utterance, $\mathrm{W}=$ individual word, $\mathrm{NR}=$ not reported, $\mathrm{ST}=$ statement. 
Table 3

Results of Studies of the Association between Parental Verbal Communication and Non-diagnostic Child Anxiety Outcomes

\begin{tabular}{|c|c|c|c|c|}
\hline \multirow[b]{2}{*}{ Study } & \multicolumn{3}{|c|}{ Type of verbal communication (Effects) } & \multirow[b]{2}{*}{ Outcome(s) } \\
\hline & Threat-related & Positive & General & \\
\hline Brumariu \& Kerns (2015) & -- & -- & Elaboration $(\downarrow)$ & Self-reported anxiety symptoms \\
\hline Hane \& Barrios (2011) & Threat initiation $(-)$ & Threat minimization $(-)$ & -- & Parent-reported anxiety symptoms \\
\hline & Threat expansion $(\uparrow)$ & & & \\
\hline Muris et al. (2010) & Negative (threat) statements $(\uparrow)$ & -- & -- & Self-reported fear \\
\hline Remmerswaal et al. (2010) & Negative (threat) statements $(\uparrow)$ & -- & -- & Self-reported fear \\
\hline Remmerswaal et al. (2013) & Negative (threat) statements $(-)^{\mathrm{a}},(\uparrow)^{\mathrm{b}}$ & Positive statements $(-)^{\mathrm{a}},(\downarrow)^{\mathrm{b}}$ & -- & Self-reported fear \\
\hline
\end{tabular}

Note. $\uparrow=$ increase in (or presence of) verbal communication feature significantly associated with increase in or higher fear/anxiety; $\downarrow=$ increase in (or presence of verbal communication feature significantly associated with decrease in or lower fear/anxiety; $-=$ verbal communication not significantly associated with outcome.

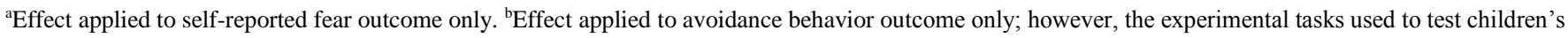
avoidance behavior did not allow differentiating between the effects of negative and positive verbal communication (i.e., it is not clear whether increased avoidance behavior was due to the effect of increased negative verbal communication or/and decreased positive information). 
Results of Studies of the Association between Parental Verbal Communication and Child Anxiety Disorder

Type of verbal communication (Effects)

\begin{tabular}{|c|c|c|c|c|c|c|}
\hline Study & Threat-related & Otherwise negative & Controlling & Positive & General & Outcome \\
\hline Dadds et al. (1996) & $\begin{array}{l}\text { Threat description }(-) \\
\text { Avoidant solution }(-) \\
\text { Negative consequence }(-) \\
\text { Overall threat }(\uparrow)^{\mathrm{a}}\end{array}$ & Aggressive solution $(\downarrow)^{\mathrm{b}}$ & -- & $\begin{array}{l}\text { Pro-social solution }(-) \\
\text { Positive consequence }(\downarrow)^{\mathrm{c}}\end{array}$ & $\begin{array}{l}\text { Agreement }(\downarrow)^{\mathrm{d}},(\downarrow)^{\mathrm{e}} \\
\text { Disagreement }(-)\end{array}$ & $\pm \mathrm{AD}$ \\
\hline Hosey \& Woodruff-Borden (2012) & -- & Negative emotion words $(\uparrow)$ & $\begin{array}{l}\text { Second-person pronouns }(\uparrow) \\
\text { Negations }(\downarrow) \\
\text { Words of exclusion }(\uparrow)\end{array}$ & -- & $\begin{array}{l}\text { First-person pronouns }(-) \\
\text { First-person plural pronouns }(-)\end{array}$ & $\pm \mathrm{AD}$ \\
\hline Hummel \& Gross (2001) & -- & Negative feedback $(\uparrow)$ & $\begin{array}{l}\text { Commands }(-) \\
\text { Suggestions }(\downarrow)\end{array}$ & Positive feedback $(\downarrow),(\downarrow)^{\mathrm{f}}$ & $\begin{array}{l}\text { Explanations }(\downarrow) \\
\text { Questions }(-)\end{array}$ & $\pm \mathrm{SP}$ \\
\hline Moore et al. (2004) & Catastrophizing $(\uparrow)^{g}$ & -- & -- & -- & -- & $\pm \mathrm{AD}$ \\
\hline Murray et al. (2014) & Threat attribution $(\uparrow)^{\mathrm{h}}$ & -- & -- & Autonomy promotion $(-)$ & -- & $\pm \mathrm{SP}$ \\
\hline Schrock \& Woodruff-Borden (2010) & -- & Negative interaction $(\uparrow)^{\mathrm{i}},(\uparrow)^{\mathrm{j}}$ & Over-control (一) & Productive engagement $(-)^{\mathrm{k}},(\uparrow)^{1}$ & -- & $\pm \mathrm{AD}$ \\
\hline Suveg et al. (2005) & -- & Negative emotion words ( - ) & -- & Positive emotion words ( $\downarrow$ ) & $\begin{array}{l}\text { Explanatory language (一) } \\
\text { Discouragement of emotion talk ( })\end{array}$ & $\pm \mathrm{AD}$ \\
\hline Suveg et al. (2008) & -- & -- & -- & -- & $\begin{array}{l}\text { Emotion words }(\downarrow)^{\mathrm{m}} \\
\text { Explanatory language }(\downarrow)^{\mathrm{n}} \\
\text { Discouragement of emotion talk }(\uparrow)^{\mathrm{o}}\end{array}$ & $\pm \mathrm{AD}$ \\
\hline Turner et al. (2003) & Cautionary statements $(-)^{\mathrm{p}}$ & Critical statements $(-)^{\mathrm{p}}$ & Directing statements $(-)^{\mathrm{p}}$ & Encouraging statements $(-)^{\mathrm{p}}$ & -- & $\pm \mathrm{AD}$ \\
\hline Whaley et al. (1999) & Catastrophizing $(\uparrow)^{\mathrm{q}},(-)^{\mathrm{r}}$ & -- & -- & -- & -- & $\pm \mathrm{AD}$ \\
\hline
\end{tabular}

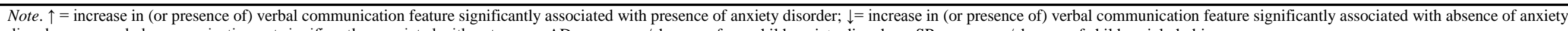
disorder; $-=$ verbal communication not significantly associated with outcome. $\pm \mathrm{AD}=$ presence/absence of any child anxiety disorder; $\pm \mathrm{SP}=$ presence/absence of child social phobia.

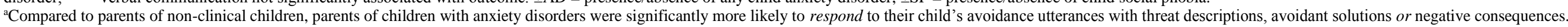

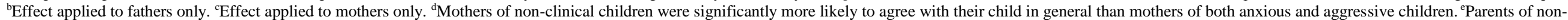

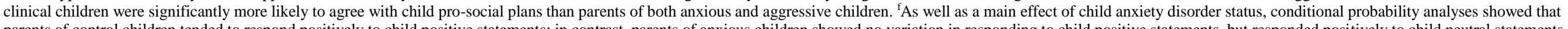

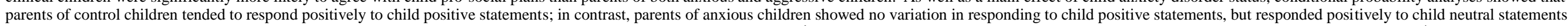

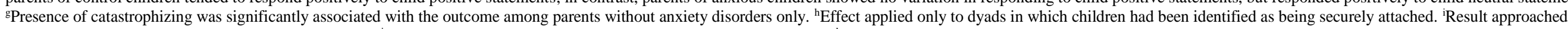

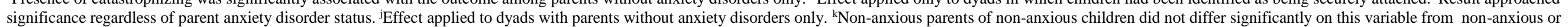

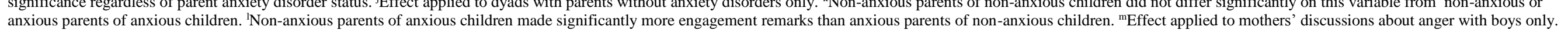

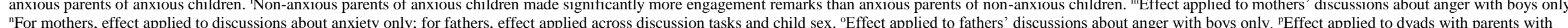

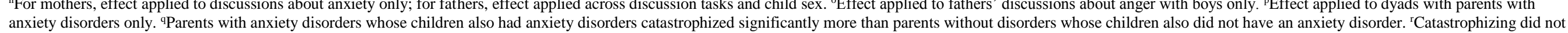
account for a significant proportion the variance in the outcome after controlling for other significant predictors (i.e., parental anxiety disorder status and family strain). 